\title{
Challenging modeling strategies for LES of non-adiabatic turbulent stratified combustion
}

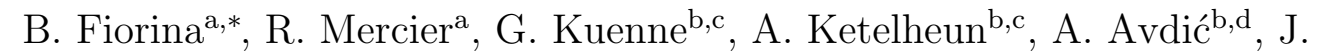

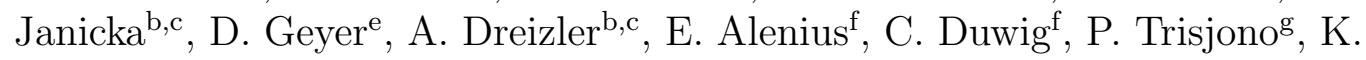
Kleinheinz $^{\mathrm{g}}$, S. Kangh ${ }^{\mathrm{h}}$ H. Pitsch ${ }^{\mathrm{g}}$, F. Proch ${ }^{\mathrm{i}}$, F. Cavallo Marincola ${ }^{\mathrm{i}}$, A. $\mathrm{Kempf}^{\mathrm{i}}$

${ }^{a}$ Laboratoire EM2C, CNRS, CentraleSupelec, Grande Voie des Vignes, 92290 Châtenay-Malabry, France

${ }^{b}$ Institute of Energy and Power Plant Technology, TU Darmstadt, Jovanka-Bontschits-Strasse 2, 64287 Darmstadt, Germany

${ }^{c}$ Darmstadt Graduate School of Energy Science and Engineering, TU Darmstadt, Jovanka-Bontschits-Strasse 2, 64287 Darmstadt, Germany

${ }^{d}$ Graduate School of Computational Engineering, TU Darmstadt, Dolivostrasse 15, 64293 Darmstadt, Germany

e Thermodynamik, Hochschule Darmstadt, Haardtring 100, 64295 Darmstadt, Germany

${ }^{f}$ Div. of Fluid Mechanics, Department of Energy Sciences, Lund University, SE 22100 Lund, Sweden

${ }^{g}$ Institute for Combustion Technology, RWTH Aachen University, Templergraben 64, Aachen 52056, Germany

${ }^{h}$ Department of Mechanical Engineering, Sogang University, Sinsu-dong, Mapu-gu, Seoul 121-742, Korea

${ }^{i}$ Institute for Combustion and Gasdynamics (IVG), Chair for Fluid Dynamics, University of Duisburg-Essen, Carl-Benz Strasse 199, 47048 Duisburg, Germany

\section{Abstract}

Five different low-Mach large eddy simulations are compared to the turbulent stratified flame experiments conducted at the Technical University of Darmstadt (TUD). The simulations were contributed by TUD, the Institute for Combustion Technology (ITV) at Aachen, Lund University (LUND), the EM2C laboratory at Ecole Centrale Paris, and the University of Duisburg-

\footnotetext{
*Corresponding author: benoit.fiorina@ecp.fr
} 
Essen (UDE). Combustion is modelled by a premixed flamelet tabulation with local flame thickening (TUD), a premixed flamelet progress variable approach coupled to a level set method (ITV), a 4-steps mechanism combined with implicit LES (LUND), the F-TACLES model that is based on filtered premixed flamelet tabulation (EM2C), and a flame surface density approach (UDE). An extensive comparison of simulation and experimental data is presented for the first two moments of velocity, temperature, mixture fraction, and major species mass fractions. The importance of heat-losses was assessed by comparing simulations for adiabatic and isothermal boundary conditions at the burner walls. The adiabatic computations predict a flame anchored on the burner lip, while the non-adiabatic simulations show a flame lift-off of one half pilot diameter and a better agreement with experimental evidence for temperature and species concentrations. Most simulations agree on the mean flame brush position, but it is evident that subgrid turbulence must be considered to achieve the correct turbulent flame speed. Qualitative comparisons of instantaneous snapshots of the flame show differences in the size of the resolved flame wrinkling patterns. These differences are a) caused by the influence of the LES combustion model on the flame dynamics and b) by the different simulation strategies in terms of grid, inlet condition and numerics. The simulations were conducted with approaches optimised for different objectives, for example low computational cost, or in another case, short turn around.

Keywords: 
Large Eddy Simulation, Turbulent stratified combustion, Tabulated

chemistry, Heat losses, Non-adiabatic, Model comparison

\section{Corresponding author:}

- B. Fiorina

- Laboratoire EM2C-CNRS, Ecole Centrale Paris F-92290, Châtenay Malabry, France

- phone: (+33)141131086

- fax: (+33)1 47028035

- e-mail: benoit.fiorina@ecp.fr

\section{Introduction}

The simulation of turbulent combustion has received much attention due to its importance for power generation and transportation. Numerical simulations of applied combustion systems were pioneered in the late seventies in the Reynolds Averaged Navier Stokes (RANS) framework, and 20 years later in the context of Large Eddy Simulation (LES), which resolves the large scale dynamics of a flame.

An LES grid is typically coarser than the thickness of a (stratified) premixed flame and even some of the flame wrinkling patterns. The chemical reaction rates are complex, cover a wide range of time-scales, and lead to a 
stiff system of equations. As a result, most chemical species cannot be resolved on the meshes that are used for industrial applications, so that subgrid scale modeling is needed for the flame structure and its interactions with the turbulence. A recent review of strategies to include combustion chemistry in LES is proposed in [1]. For premixed and stratified combustion, different methods have been developed to capture the propagation of the filtered wrinkled flame fronts, without having to resolve all species contained in the chemical mechanism. Some of these strategies are described below.

A first approach is the Artificial Flame Thickening (ATF) or Thickened Flame Model (TFLES), which artificially thickens the flame front by modifying the diffusion coefficient and the pre-exponential constant $[2,3,4]$. This approach is robust and has been applied to complex combustors, using a global chemistry assumption [5]. Detailed chemistry effects can been accounted for by coupling ATF methods with tabulated chemistry techniques for adiabatic [6] and non-adiabatic flames [7].

An alternative is the use of a filter of (at least) the size of the grid spacing. The Flame Surface Density (FSD) concept for LES [8] is based on this idea, which was initially developed for infinitely thin flames and later extended for flames of finite thickness [9]. This strategy has been retained to introduce tabulated chemistry through the Filtered Tabulated Chemistry for LES (F-TACLES) model [10]. The F-TACLES formalism has been developed to capture the filtered flame propagation in complex reactive flow configurations, such as stratified [11] or non-adiabatic flames [12]. 
Another approach is to solve a smooth scalar field where an iso-surface is defined to represent the instantaneous position of the premixed flame front. This level set or G-equation model has been proposed in the RANS context [13], and was amongst the first models applied to LES [14]. The mathematical formalism of the G-equation has been updated for LES in the corrugated flamelet regime [15] and in the thin reaction zones regime [16, 17].

However, one can also apply an LES on a very find grid, with a resolution sufficient to resolve the flame thickness and wrinkling patterns. This results in a Direct Numerical Simulation (DNS) of the flame front, so that no subgrid model contributions for the reaction rate modelling are needed. The approach is here referred to as "No Combustion Model (NCM)", linked to a (small) detailed reaction mechanism that is solved directly in the LES [18, 19]. The method does however require a sufficient grid resolution and a much reduced chemical mechanism without stiff species like $\mathrm{CH}$ or $\mathrm{HCO}$.

All these turbulent combustion models have different requirements in terms of grid resolution and numerical scheme. Research groups have therefore developed their own strategies, which involve the combination of the turbulence and combustion models, the numerical schemes, the prescription of boundary conditions, computer hardware, and further choices made by the user. The results of five different strategies are presented and compared in the present paper. The aim of the paper is to illustrate the state of the art in stratified turbulent combustion modelling, as demonstrated for different strategies of different groups. It should be noted that this comparison goes 
far beyond a comparison of sub-models (e.g. for the reaction source term or for the turbulent flux only), which could be conducted by a single group, but might be affected by a shortcoming in the computational approach. Indeed, the collaboration of five different groups has led to the recognition of certain critical modeling aspects that will be discussed in this paper.

The target for the comparison is the turbulent stratified flame configuration investigated by laser diagnostics at Technische Universität Darmstadt (TUD) [20, 21]. This case is strongly influenced by interactions between turbulence, chemistry, heat transfer and fuel/air mixing. It features a relatively simple geometry but encompasses a large range of complex phenomena. Given these advantages and the timely availability of the experimental data, this case was chosen as a target for the TNF workshop, and hence for the comparison presented in the present paper.

Five groups are involved: The Institute of Energy and Power Plant Technology at TUD, the EM2C laboratory at Ecole Centrale Paris (EM2C), the Institute for Combustion Technology (ITV) at RWTH Aachen, Lund University (LUND), and the University of Duisburg-Essen (UDE). All groups employ different flow solvers, which all rely on low Mach number assumptions to achieve an efficient time integration. The TUD applies a premixed flamelet tabulation using ATF, EM2C applies the F-TACLES model, ITV uses a Gequation formalism coupled to a flamelet progress variable approach, LUND describes the combustion chemistry through a 4-steps mechanism combined with NCM, and UDE uses an FSD approach that assumes an infinitely thin 
flame front.

The simulations differ by the modeling approach, the CFD code, the combustion chemistry, numerical techniques, computational meshes - and other choices made by the user. In spite of these differences, each of these computational strategies is designed to capture the filtered flame propagation speed when subgrid scale flame wrinkling occurs (with the exception of NCM) or when the flame wrinkling is fully resolved. The models account for nonadiabatic effects on the combustion chemistry, so that they are able to capture quenching phenomena induced by heat losses at the burner. As a result, all methods should be able to capture the same global flame properties.

Section 2 gives more details on the turbulent combustion models and their differences and similarities. Section 3 describes the target experiment configuration, and section 4 presents the different computational setups. The results are then presented and discussed in section 5 .

\section{Turbulent Combustion Models}

\subsection{Filtered Tabulated Chemistry for LES (EM2C)}

The Filtered Tabulated Chemistry model captures a stratified flame front using the mixture fraction $Z$ and the progress variable $Y_{c}$. The mixture fraction $Z$, equal to 0 and 1 in oxidizer and fuel streams, respectively, captures the fuel-air mixing, whereas the progress variable $Y_{c}$ (here defined as $\mathrm{CO}_{2}$ mass fraction) tracks the flame front. The F-TACLES formalism closes the

filtered progress variable $\tilde{Y}_{c}$ equation in the flamelet regimes $[10,11,12]$. The 
SGS laminar contributions to molecular diffusion, convection and chemical reaction are tabulated by filtering 1-D adiabatic premixed flame elements computed with detailed chemistry and transport. Balance equations for the filtered mixture fraction $\widetilde{Z}$ and the mixture fraction variance $\widetilde{Z^{\prime \prime 2}}$ [11] are solved in addition to the $\widetilde{Y}_{c}$ transport equation.

By definition, this model propagates the resolved flame front at the subgrid scale turbulent flame speed $S_{T, \Delta}[11,12]$ :

$$
\rho_{0} S_{T, \Delta}=\Xi_{\Delta} \gamma \int_{0}^{1} \rho_{0}{S_{l}}^{a d}\left(Z^{\prime}\right) P\left(Z^{\prime}\right) d Z^{\prime}
$$

In this equation, $S_{l}^{a d}(Z)$ is the consumption speed of a freely propagating adiabatic laminar premixed flame within fresh gases of mixture fraction $Z$. The sub grid scale flame front wrinkling factor is denoted to by $\Xi_{\Delta}$.

The mixture fraction Filtered Density Function $(\mathrm{FDF}) \widetilde{P}(Z)$ is modeled by a $\beta$ function characterized by the filtered mixture fraction $\widetilde{Z}$ and the subgrid scale mixture fraction variance $\widetilde{Z^{\prime \prime 2}}$. The coefficient $\gamma$ accounts for heat losses [12] and is defined as follows:

$$
\gamma=\frac{\int_{0}^{1} \rho_{0} S_{l}\left(Z^{\prime}, \Delta \widetilde{h}\right) P\left(Z^{\prime}\right) d Z^{\prime}}{\int_{0}^{1} \rho_{0} S_{l}^{a d}\left(Z^{\prime}\right) P\left(Z^{\prime}\right) d Z^{\prime}}
$$

The enthalpy defect relative to the fresh gases is defined as $\Delta h=h^{a d}(Z)-$ $h(Z)$, where $h$ is the chemical plus sensible enthalpy and superscript ad 
refers to adiabatic conditions. The $S_{l}\left(Z^{\prime}, \Delta \widetilde{h}\right)$ and the laminar consumption speed at a given $\Delta h$ is estimated from burner-stabilized 1-D flames [22]. In adiabatic flows, $\gamma$ equals 1 and decreases when heat losses slow down combustion chemistry, to the limit of a quenched flame for $\gamma=0$.

\subsection{Combined artificial thickening and tabulated chemistry approach (TUD)}

This model combines artificial flame thickening (ATF) with tabulated chemistry [6]. Balance equations for the mixture fraction and progress variable are solved in addition to the flow governing equations. The ATF implementation follows the procedure of Colin et al. [4], for which the efficiency function is evaluated by using the non-dynamic formulation by Charlette et al. [23]. A flame sensor is used to ensure that the ATF modifications are only applied within the flame front. Furthermore, the thickening factor is based on the local cell size to keep the modeled part as small as possible. The tabulation is based on the flamelet generated manifolds (FGM) methodology [24], which uses the mixture fraction $Z$ and the progress variable $Y_{c}$ (here $\mathrm{CO}_{2}$ mass fraction). Some particularities of the modeling approach imposed by this burner were discussed in the context [21] of previous work based on an adiabatic assumption. Heat losses have been included in the present work through enthalpy as a third table access parameter [7].

\subsection{Coupled G-equation / progress variable formalism (ITV)}

The chemistry is tabulated from 1-D premixed laminar flamelets in terms of the progress variable $Y_{c}$ and the mixture fraction $Z$. The progress variable 
is defined as the sum of the mass fractions of some major intermediates and products as $Y_{c}=Y_{\mathrm{H}_{2} \mathrm{O}}+Y_{\mathrm{CO}_{2}}+Y_{\mathrm{CO}}+Y_{\mathrm{H}_{2}}$. The impact of heat losses on thermo-chemical quantities is captured by the enthalpy defect, a variable independent of the mixture fraction. [25].

It is assumed that enthalpy defect fluctuations at the sub-filter level are small, from which follows that a $\delta$-function PDF for the enthalpy defect is suitable. Assuming statistical independence of mixture fraction $Z$ and the normalized reaction progress variable $C$, the filtered reactive scalars are computed for a $\beta$-PDF for both the mixture fraction and the progress variable.

To prevent errors that originate from the lack of flame front resolution, the progress variable describing the resolved parts of the flame is coupled with a level set equation to ensure proper turbulent flame propagation even when the progress variable is underresolved [26].

The coupling is implemented via the modeling of the progress variable source term, which is formulated in a way that it depends solely on the level set in the vicinity of the flame and purely on the progress variable itself away from the flame. The transition between these two extremes is modeled by a blended exponential function. In this coupling, the progress variable captures the thickening of the flame in the thin reaction zones regime, while the level set ensures that the flame propagates at the correct velocity. 


\subsection{Flame Surface Density Model (UDE)}

A transport equation is solved for the normalized reaction progress variable. The sum of the molecular diffusion and the reaction source term is computed from the product of the laminar flame propagation speed and the flame surface density, where the latter considers the unresolved wrinkling of the flame on the sub-filter level.

The laminar flame speed and the temperature of the burnt gas are evaluated from higher-order polynomials as a function of the mixture fraction, which is obtained from an additional transport equation. The polynomials were fitted to results from freely-propagating flame computations with the GRI3.0 [27] mechanism and a Lewis number of unity assumption for all species. For the non-adiabatic computations, a third transport equation is solved for the enthalpy defect, which is then used to determine correction factors for the laminar flame speed and the burnt temperature from polynomial fits, where the coefficients depend on mixture fraction. The correction factors were obtained from freely-propagating flames with heat loss [28].

The flame surface density is determined from the model proposed by Fureby [29], which was used in the slightly modified version of Ma et al. [30] to obtain the correct limiting behavior for a laminar flame. A countergradient transport model is used to reduce the artificial thickening of the flame brush. In contrast to the already existing adiabatic FSD computations of this burner [31], the last $20 \mathrm{~mm}$ of the burner geometry has been included in the computational domain to obtain more realistic flow conditions at the 
burner exit.

\section{5. "No Combustion Model" (LUND)}

With "No Combustion Model" (NCM), the sub-grid contributions to the reaction rate modeling are neglected so that the filtered reaction rate of the species $i$ is modelled as:

$$
\overline{\dot{\omega}_{i}\left(Y_{j}, T\right)}=\dot{\omega}_{i}\left(\tilde{Y}_{j}, \widetilde{T}\right)
$$

The reaction rate $\dot{\omega}_{i}$ is obtained from an Arrhenius expression. Equation 3 assumes that species concentrations and temperature are homogeneous within each filter volume (grid cell). For distributed combustion regimes, this is the case with very intense sub-grid mixing [18]. For the corrugated flamelet regime, NCM is suitable when the LES grid resolution is sufficiently fine to resolve the subgrid scale flame wrinkling.

For a practical LES-grid, the expression may approximate the reaction rate reasonably well when the flame lies in or close to the distributed reaction zone regime, or when stratification or heat losses weaken the reaction and thus thicken the flame, as reported elsewhere [18, 19, 32, 33, 34]. The choice of chemical mechanism will also influence the validity of the "no-combustion model": unlike global mechanisms, detailed chemical schemes include radical species with very short characteristic time and length scales. Thinner reac-

tion layers must therefore be considered with complex chemistry, so that the mesh resolution must be refined. 


\subsection{Models and their properties}

\subsubsection{Chemistry modeling}

Among the five turbulent combustion models, three are based on the tabulation of premixed flamelet elements, well adapted to capture the chemical structure of stratified flame [35]. ATF-FGM, F-TACLES and the coupled G-C equations are based on laminar premixed flame archetypes computed using the detailed chemical schemes of GRI (3.0) [27] (53 species, 325 reactions), by Lindstedt [36] (29 species, 300 reactions), and by Peters and Rogg (28 species) [37]. The flamelets that are used for chemistry tabulation in the ATF-FGM formalism are computed with a unity Lewis number assumption, whereas differential diffusion is considered in the generation of the database for F-TACLES and the G-C equation. The NCM strategy employs 7-species (CH4, CO, H2, O2, CO2, H2O, N2) with the 4-step global mechanism by Jones and Lindstedt [38]. Finally, the FSD method uses premixed flamelet solutions computed with the GRI 3.0 mechanism [27] with a Lewis number of unity to compute the laminar flame consumption speed. The adiabatic flame temperature from all approaches agrees well, as can be seen from the mean temperature on the center-line in Fig. 3. The thermal flame thicknesses, defined as $\delta_{l}=\left(T^{b}-T^{u}\right) / \operatorname{Max}|\nabla T|$ (at an equivalence ratio $\phi=0.9$ ), is approximately equal to $0.5 \mathrm{~mm}$ for all schemes.

Figure 1 shows the laminar consumption speed as a function of the equivalence ratio. For the range of equivalence ratio covered in the TSFA configuration, the detailed mechanisms used by TUD, UDE, EM2C and ITV agree 


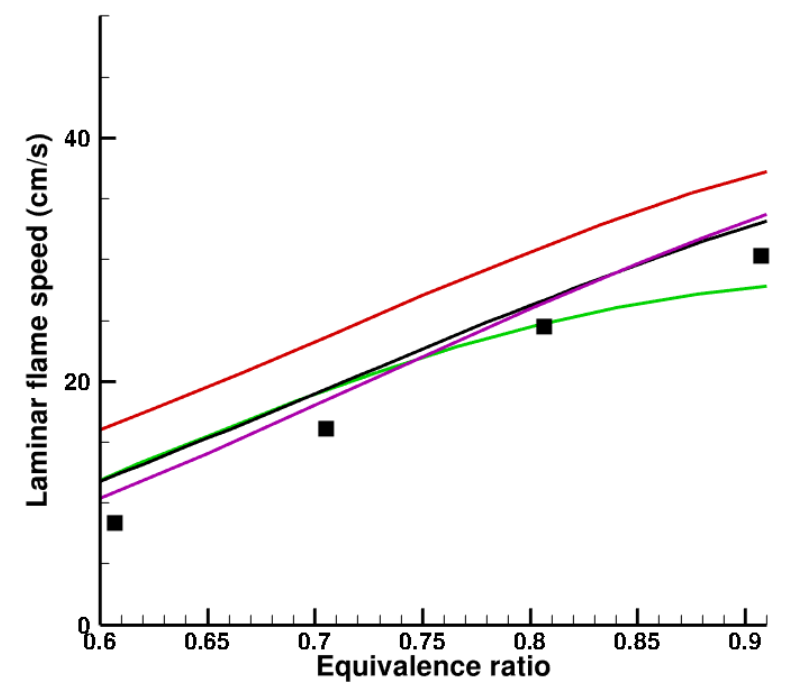

Figure 1: Laminar flame speed of an unstretched premixed planar flame predicted by the combustion chemistry schemes used by TUD-UDE (green), EM2C (black), ITV (purple), LUND (red). The symbols refer to data measured in experiments [39].

fairly well on the predictions of the laminar flame consumption speed, a key quantity in premixed and stratified combustion LES. Differences are only observed with the very compact global mechanism by Jones and Lindstedt [38] (LUND), for which the flame speed is slightly overestimated.

The differences in the predicted laminar flame speed, which result from differences in the reaction mechanisms, have therefore a significant impact on flame propagation. One may, for example, expect that the faster flame speed used by LUND will partially compensate for the fact that the group does not apply a subgrid model (NCM), so that their "turbulent flame speed" would otherwise be underestimated. It should however be stressed that the different flame speeds shown in Fig. 1 are representative of practices in turbulent 
combustion modeling, and that the differences represent the uncertainty in chemical kinetics.

\subsubsection{Flame resolution}

A recurrent problem in premixed and stratified combustion LES is that the flame is often thinner than the LES grid size. This is particularly true for high pressure flames or large and complex industrial devices. As chemical reaction rates are very stiff, the flame front cannot be directly resolved on practical LES meshes. The solution followed by ATF-FGM and F-TACLES is to artificially thicken the flame front to enable the numerical resolution of the chemical reaction rate. The ATF-FGM [4] artificially thickens the flame through a "thickening factor" F, whereas F-TACLES [10] introduces a filter larger than the mesh size in order to be able to resolve the flame structure.

The FSD model applied by UDE does not explicit monitor the numerical resolution of the reactive layer. The effective flame thickness is in practice thickened by both the numerical diffusion and the counter gradient transport model. Therefore, unlike to ATF-FGM and F-TACLES, the flame thickness is not explicitly controlled. This well-known issue of FSD models has been addressed by Ma et al. [30] and others, but is avoided by the ATF/FGM approach that is also often used by the UDE group [40]. With NCM, the flame is thickened by the increased effective diffusion resulting from the diffusive TVD scheme for scalar transport.

The coupled G-C equation utilizes a level-set technique that tracks the 
inner layer position of the flame front [16].

All computational strategies employ different methods to track the filtered flame front. All methods achieve a proper prediction of combustion when the flame wrinkling is resolved. In particular, for planar fronts, all models predict that the filtered flame consumption speed will equal the laminar consumption speed. This property is of crucial importance to capture the dynamics of the target flame investigated here, in particular near the flame base where the reaction zone is hardly wrinkled yet by the turbulence. An overview of model characteristics is shown in Table 1.

\begin{tabular}{ccccc}
\hline \hline $\begin{array}{c}\text { Turbulent } \\
\text { Combustion model }\end{array}$ & Chemistry & Kinetic & Flame resolution & Flame wrinkling \\
management & model \\
\hline \hline ATF-FGM & Tabulated chemistry & GRI3.0 Lewis number unity & Thickening & Charlette et al. \\
$($ TUD $)$ & (premixed flamelets) & {$[27]$} & & {$[23]$} \\
\hline F-TACLES & Tabulated chemistry & Lindstedt & Filtering & Charlette et al. \\
$($ EM2C $)$ & (premixed flamelets) & {$[36]$} & & {$[23]$} \\
\hline Coupled G-C & Tabulated chemistry & Peters \& Rogg & Level-set & Pitsch \\
$($ ITV $)$ & (premixed flamelets) & {$[37]$} & & {$[16]$} \\
\hline NCM & Semi-global & Jones \& Lindstedt & Resolved & None \\
$($ LUND $)$ & scheme & {$[38]$} & & Fureby \\
\hline FSD & Flame speed & GRI3.0 Lewis number unity & None & {$[29]$} \\
$($ UDE $)$ & tabulation & {$[27]$} & (see Sec. 2.6.2) & \\
\hline
\end{tabular}

Table 1: Summary of main turbulent combustion models properties. 


\subsubsection{Modeling SGS flame turbulence interactions}

Four models are based on a geometrical representation of flame turbulence interactions: ATF-FGM, F-TACLES, coupled G-C and FSD, which all require an explicit modeling of the SGS flame wrinkling. The ATF-FGM and F-TACLES employ the Charlette et al. [23] model. The hybrid G-C method model the turbulent burning velocity is determined using the formula developed by Peters [41] for a RANS context and adapted for LES by Pitsch [16]. The FSD formulation uses the fractal flame wrinkling model proposed by Fureby [29], whereas NCM does not account for sub-filter flame turbulence interactions at all.

\section{Experimental configuration}

The unconfined Turbulent Stratified Flame (TSF) [20] examined at Technische Universität Darmstadt consists of three $5 \mathrm{~mm}$ staged concentric tubes placed in a $0.1 \mathrm{~ms}^{-1}$ air co-flow. Inlet bulk velocity and mixture conditions are indicated in Fig. 2 for the case TSF-A. Burnt gases exit from the central pilot tube to stabilize the flame. Pilot, first and second tubes are denoted by subscripts $p, 1$ and 2 respectively. Inner radii are $7.4 \mathrm{~mm}, 18.5 \mathrm{~mm}$ and $30.0 \mathrm{~mm}$, with corresponding lip thicknesses of $0.75 \mathrm{~mm}, 0.5 \mathrm{~mm}$ and 0.5 mm. Hydraulic diameters $D h$, equivalence ratios $\phi$ and Reynolds numbers Re are given in Table 2 for both the non-reacting case TSF-A-i1 with only the pilot flame burning and for the reacting case TSF-A-r. Bulk velocities $v=\dot{m} /\left(\rho^{f} \cdot A^{e x i t}\right)$, computed from the fresh gas density $\rho^{f}$ and the exit area 
of each tube $A^{\text {exit }}$, are also indicated.

The pilot wall, made of ceramic, is not perfectly insulating so that heat transfer takes place between the pilot and slot 1. A RANS 2D-axisymmetric computation of the flow inside the burner, coupled to a heat conduction calculation inside the burner wall (between the pilot and slot 1) [12] has shown that the temperature is quasi-homogeneous within the wall, at around $750 \mathrm{~K}$.

\begin{tabular}{|c|c|c|c|c|c|c|c|c|c|c|c|}
\hline Case & $\phi_{p}$ & $\begin{array}{c}v_{p} \\
\left(\mathrm{~m} \cdot \mathrm{s}^{-1}\right)\end{array}$ & $\begin{array}{l}D h_{p} \\
(\mathrm{~mm})\end{array}$ & $\phi_{1}$ & $\begin{array}{c}v_{1} \\
\left(\mathrm{~m} \cdot \mathrm{s}^{-1}\right)\end{array}$ & $\begin{array}{l}D h_{1} \\
(\mathrm{~mm})\end{array}$ & $R e_{1}$ & $\phi_{2}$ & $\begin{array}{c}v_{2} \\
\left(\mathrm{~m} . \mathrm{s}^{-1}\right)\end{array}$ & $\begin{array}{l}D h_{2} \\
(\mathrm{~mm})\end{array}$ & $R e_{2}$ \\
\hline TSF-A-i1 & 0.9 & 1 & 14.8 & 0 & 10 & 20.0 & 13800 & 0 & 10 & 20.0 & 13300 \\
\hline TSF-A-r & 0.9 & 1 & 14.8 & 0.9 & 10 & 20.0 & 13800 & 0.6 & 10 & 20.0 & 13300 \\
\hline
\end{tabular}

Table 2: Details about operating conditions for both reacting and inert (pilot burning only) cases.

\section{Computational parameters}

\subsection{Flow solvers}

The numerical properties of each code are indicated in Tab. 3. The numerical schemes influence the minimal resolution required to ensure the correct flame speed. For instance, the truncation error from the convective term is expected to contribute to the dynamics of thin fronts. Therefore, each group has chosen a mesh resolution compatible with their model, the properties of their numerical scheme, the computational efficiency of the code, and 
affordable with their resources.

\begin{tabular}{|c|c|c|c|c|c|c|}
\hline \multirow[t]{2}{*}{ Group } & Code & grid & spatial & temporal & Control & Turbulence \\
\hline & & type & scheme & scheme & Volume & SGS \\
\hline \multirow[t]{2}{*}{ TUD } & FASTEST & block & $2^{\text {nd }}$ ord. velocity $[42]$ & $2^{\text {nd }}$ order & cell & Dynamic \\
\hline & & structured & $2^{\text {nd }}$ ord. TVD for scalars $[43]$ & Runge Kutta & centered & Smag. [44] \\
\hline \multirow[t]{2}{*}{ EM2C } & YALES2 & un- & $4^{t h}$ ord. velocity & $4^{t h}$ order & node & WALE \\
\hline & & structured & $4^{\text {th }}$ ord. scalar $[45]$ & TRK4 [46] & centered & {$[47]$} \\
\hline \multirow[t]{2}{*}{ ITV } & CIAO & structured & $2^{\text {nd }}$ ord. velocity & $2^{\text {nd }}$ order & staggered & Dynamic \\
\hline & & & $3^{\text {rd }}$ ord. scalar & Crank-Nicolson & & Smag. [44] \\
\hline \multirow[t]{2}{*}{ LUND } & OpenFOAM & un & $2^{\text {nd }}$ ord. linear for velocity & $2^{n d}$ order & cell & Smag. \\
\hline & & structured & $2^{n d}$ ord. TVD for scalars & back. fin. diff. & centered & {$[48]$} \\
\hline \multirow[t]{2}{*}{ UDE } & PsiPhi & unstruct. & $2^{\text {nd }}$ ord. velocity & $3^{r d}$ order & cell & Smag. [48] \\
\hline & & equidistant & $2^{\text {nd }}$ ord. TVD for scalars & Runge Kutta & centered & $C_{s}=0.173$ \\
\hline
\end{tabular}

Table 3: CFD code characteristics

\subsection{Management of computational domain and boundary conditions}

Due to the widely varying properties of the different codes, it is not straightforward to define a unique computational domain that is suitable to all. Each group has therefore defined their own computational domain as shown in Fig. 2. The TUD performed the computation of the flow within the upstream pipe geometry, including the simulation of premixed combustion in the pilot tube [21]. In previous work [12], EM2C used a similar domain for slot 1 and slot 2 but excluded the pilot flame. The mean velocities prescribed as inlet conditions are however obtained from the numerical simulation of the flow inside the burner [21]. In contrast, ITV, UDE and LUND apply a shorter 


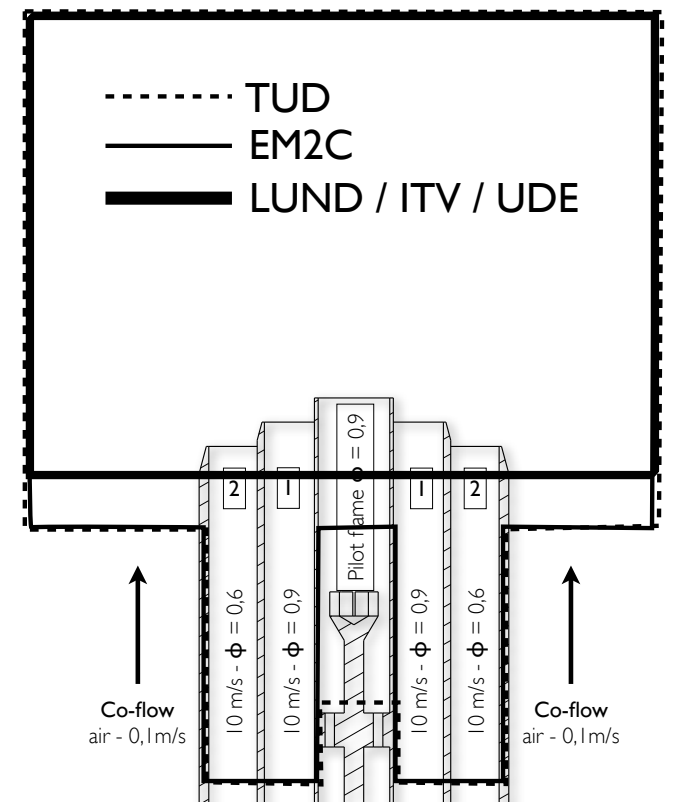

Figure 2: Computational domains.

domain upstream. To limit the effect of different computational domains on the results, a common procedure was used to prescribe the boundary conditions, as described in the following sections.

\subsubsection{Thermal boundary conditions}

Each group has contributed an adiabatic and a non-adiabatic simulation. For the adiabatic runs, an uniform pilot temperature is set to $2132 \mathrm{~K}$ (which corresponds to the equilibrium state), with no heat-transfer to the walls. In the non-adiabatic simulations, the heat-transfer between the hot products in the pilot and the first annulus through the ceramic wall is modelled by setting a fixed wall temperature of $750 \mathrm{~K}$ as estimated from an axisymmetric 
RANS computations. Please note that this estimated wall temperature would lead to an over-prediction of the temperature in the pilot stream, so that the groups have adjusted the inlet temperature of the pilot tube along the centerline at $2000 \mathrm{~K}$ to match the measured mean temperature profile at $\mathrm{z}=$ $15 \mathrm{~mm}$ (except TUD who includes the pilot flame in their computation). The wall between slots 1 and 2 are modeled as adiabatic since the temperatures are the same on either side. Figure 3 shows that the mean temperatures from the non-adiabatic simulations are in good agreements with experimental data and ensure a consistent thermal inflow boundary condition, enabling meaningful comparisons between the data sets. The temperature fluctuations shown in Fig. 3, however, are more affected by the modeling errors, the inlet turbulence level and by numerical dissipation, so that larger deviations can be observed in the fluctuations than in the mean.

\subsubsection{Velocity boundary conditions}

The origin of the axial coordinate $(z=0 \mathrm{~mm})$ is set at the exit plane of the pilot tube. Detailed velocity measurements close to the pilot exit are available for the inert configuration (TSF-A-i1), but not for the reactive (TSF-A-r) case. However, we have observed in the LES computations that the flow field at this location is little influenced by the flame burning further downstream. The measured velocity data at $z=1 \mathrm{~mm}$ of TSF-A-i1 is therefore used as a reference for the reactive flow simulations.

The velocity of the co-flow is assumed to be constant at $0.1 \mathrm{~m} / \mathrm{s}$. Streams 


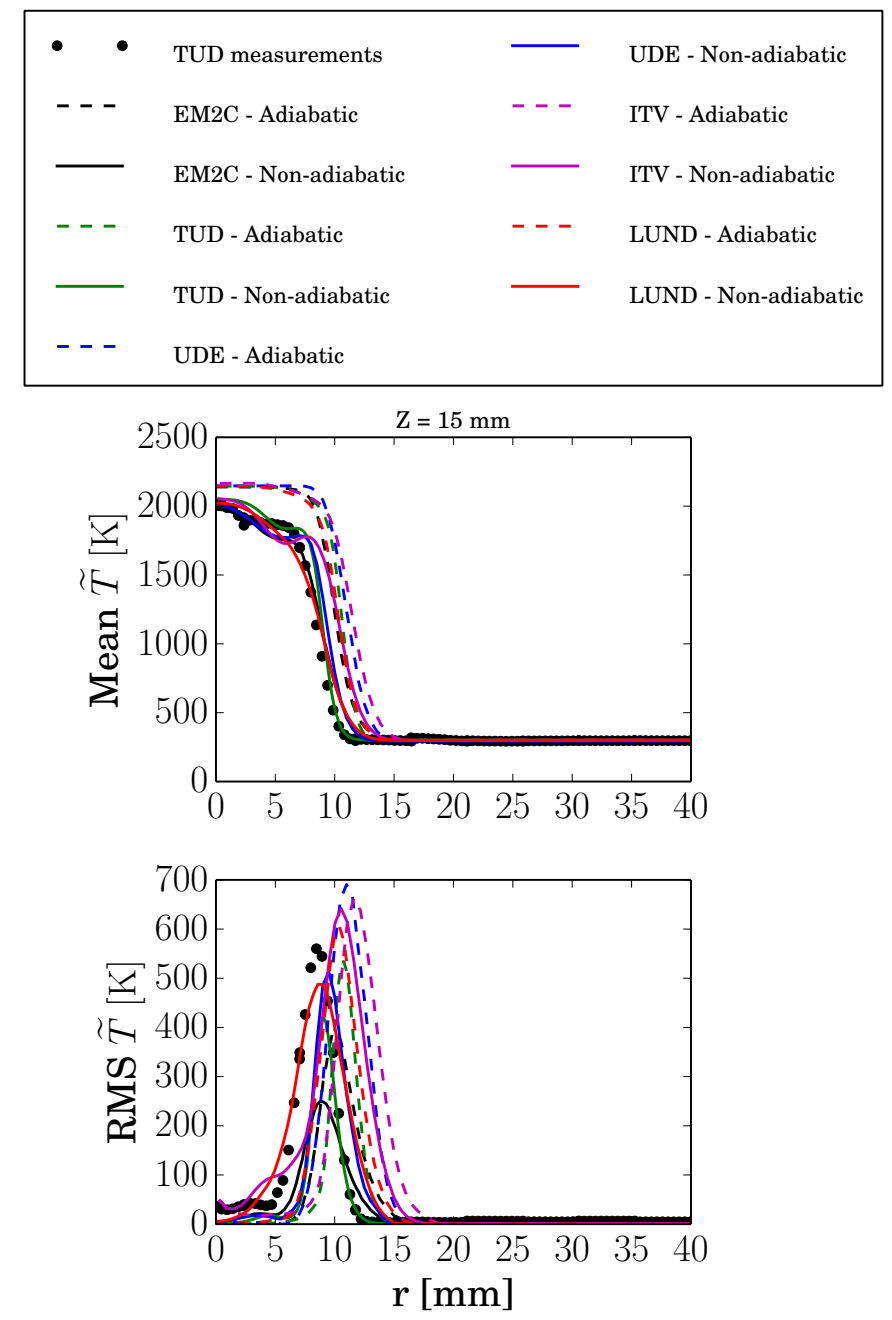

Figure 3: Temperature profiles at $z=15 \mathrm{~mm}$.

1 and 2 are quasi-isothermal, so that the means and fluctuations of their inlet velocity could be set by each group to retrieve the experimental data measured at $z=1 \mathrm{~mm}$ in the inert configuration (TSF-A-i1). A different strategy has been retained to retrieve the pilot mass flow rates measured in 
the experiments. The heat transfer between the pilot and slot 1 decreases the pilot stream temperature and hence reduces its flow speed. The mean axial inlet velocity in the pilot tube has therefore been set to satisfy the mass flow of fresh gases upstream of the pilot flame, as determined by the flowmeters in the experiment [21]. The mass flow corresponds to a bulk velocity of $U_{p}=1$ $\mathrm{m} / \mathrm{s}$ of the unburnt gas over the tube cross section. The development of turbulence within the pilot tube is directly computed by TUD, whereas the other groups had do inject artificial turbulence to match the experiments at $z=1 \mathrm{~mm}$. Figure 4 shows both adiabatic (dashed lines) and non-adiabatic (solid lines) predictions of the mean and RMS of the axial velocity over the radius at $z=1 \mathrm{~mm}$. No significant differences are observed between the adiabatic and non-adiabatic simulations at the exits of slot $1(8 \mathrm{~mm}<\mathrm{r}<18$ $\mathrm{mm})$ and slot $2(19 \mathrm{~mm}<\mathrm{r}<30 \mathrm{~mm})$. At the pilot tube, the flow field is affected by the heat transfer within the tube. As the non-adiabatic pilot stream temperature is lower than in the adiabatic state, density and mean axial velocity are affected by heat transfer, with non-adiabatic computations being closer to the experimental data.

\subsection{Summary of simulations performed}

The computational set-up specific to each group simulation is shown in Table 4. As both unstructured and structured grids have been applied to different domains, the number of nodes is not directly representative of the flame resolution. We also stress that unstructured meshes can cover both 

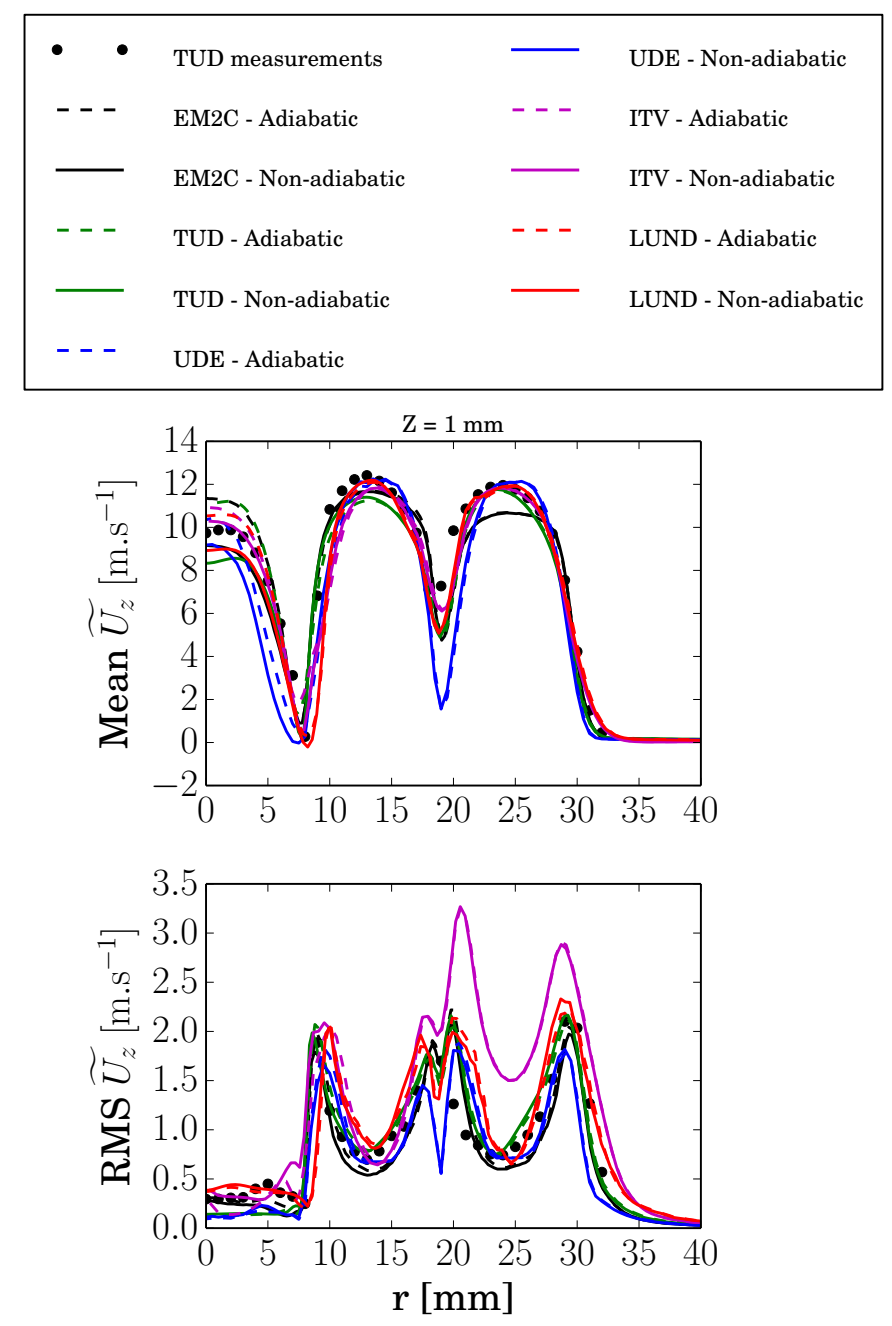

Figure 4: Axial velocity profiles at $z=1 \mathrm{~mm}$.

tetrahedral and cubical/polyhedral cells. To show the various meshes refinements, the centerline plane colored by the control volume size is shown in Fig.5. For this reason, a resolution criterion is also given, defined as $\Delta_{x} / \delta_{l}$ where $\Delta_{x}$ is the cell size in the flame region and $\delta_{l}=\left(T^{b}-T^{u}\right) / \max |\nabla T|$ is an 
estimation of the laminar thermal flame thickness, which is approximately $0.5 \mathrm{~mm}$ for all simulations. The grids of TUD, ITV and EM2C exhibit a ratio of $\Delta_{x} / \delta_{l}>1$. This issue is tackled by TUD and EM2C by artificially thickening the flame by a factor $F$ (ATF-FGM) or by filtering the chemistry

table with a flame filter that is larger than the mesh size (F-TACLES). The level set method of ITV is designed to track both infinitely thin surfaces and turbulence-broadened flames. In the FSD and NCM approaches applied by UDE and LUND, flame thickness is not controlled explicitly (as discussed in Sec. 2.6.2), and in turn, there is no explicit resolution requirement.

A complete list of adiabatic and non-adiabatic simulations is shown in Tab. 5, with details of the pilot boundary conditions.

\section{Results analysis}

\subsection{Flow field}

Mean axial and radial components of the velocity field for the case TSFA-r are shown in Figs. 6 and 7 over the radius at six axial positions $(Z=50$, 75, 100, 125, 150 and $200 \mathrm{~mm}$ ). The RMS of axial and radial velocities are plotted in Figs. 8 and 9. Dashed and solid lines correspond to adiabatic and non-adiabatic simulations, respectively, whereas colors indicate the group.

There is no perfect agreement between the different approaches, but global tendencies can be identified. For the adiabatic cases, the flow field is predicted fairly well, with the exception of the mean axial velocity (Fig. 6) at the centerline, where the impact of heat losses to pilot tube is clearly visi- 


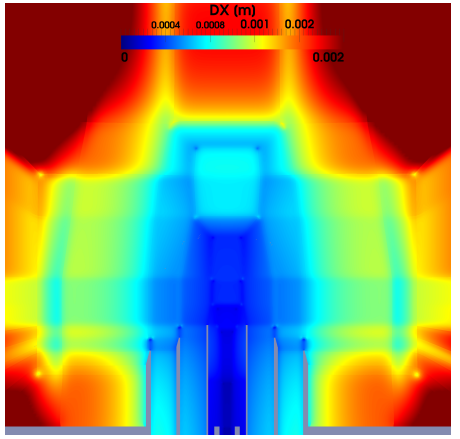

(a) TUD

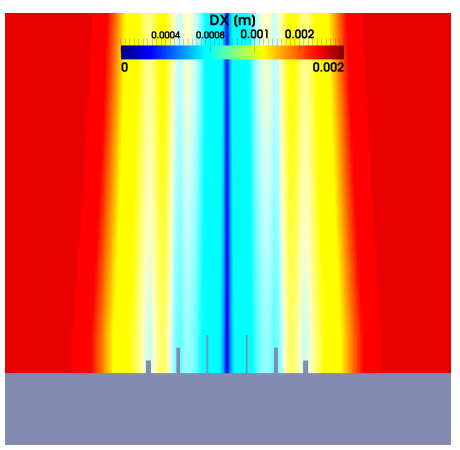

(c) ITV

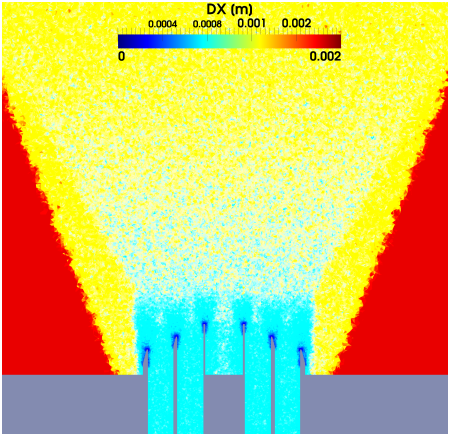

(b) EM2C

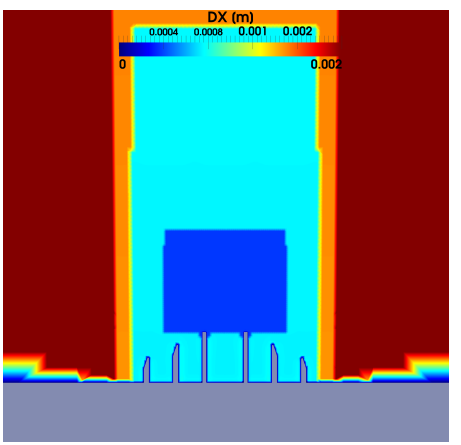

(d) LUND

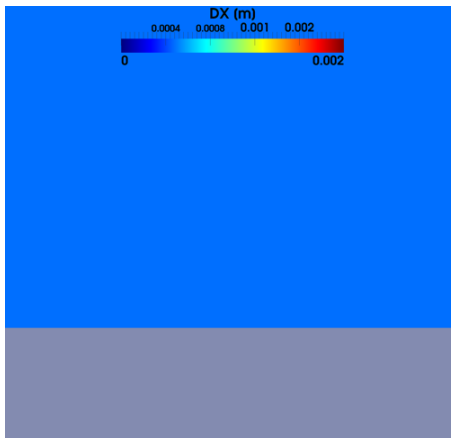

(e) UDE

Figure 5: Centerline plane colored by the control volume size 

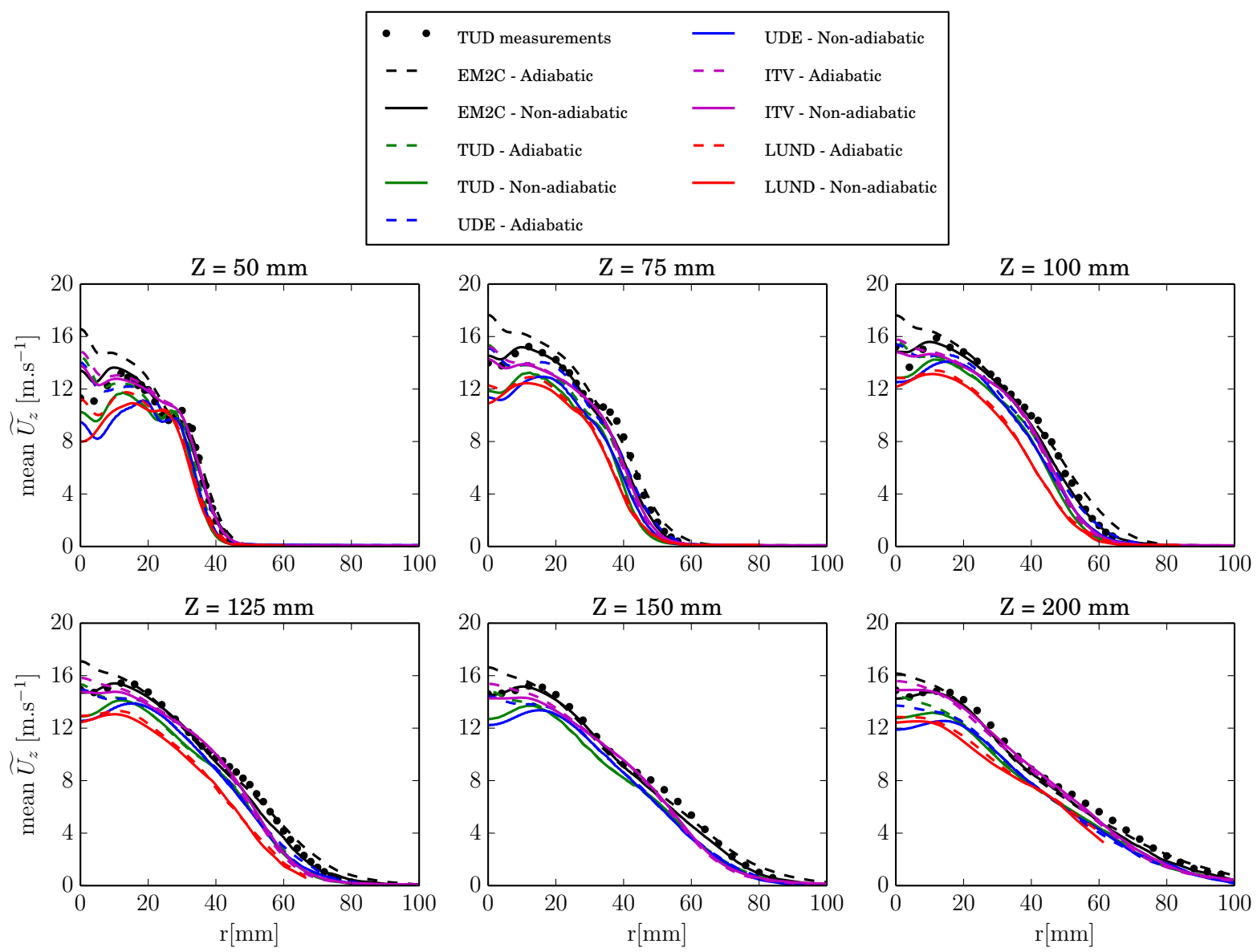

Figure 6: Mean axial velocity at different axial positions. Solid lines: non-adiabatic LES, dashed lines adiabatic LES. 


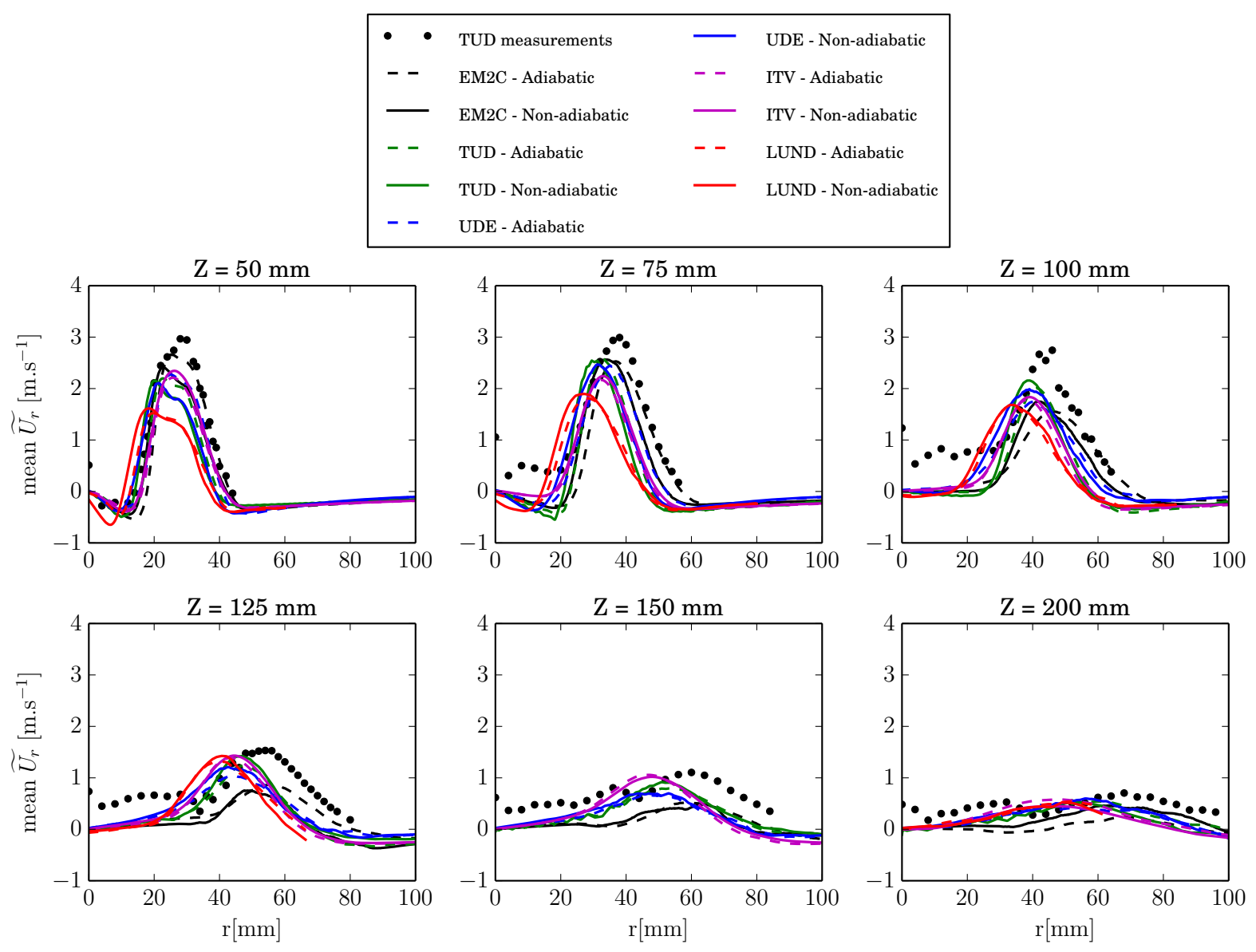

Figure 7: Mean radial velocity at different axial positions. Solid lines: non-adiabatic LES, dashed lines adiabatic LES. 


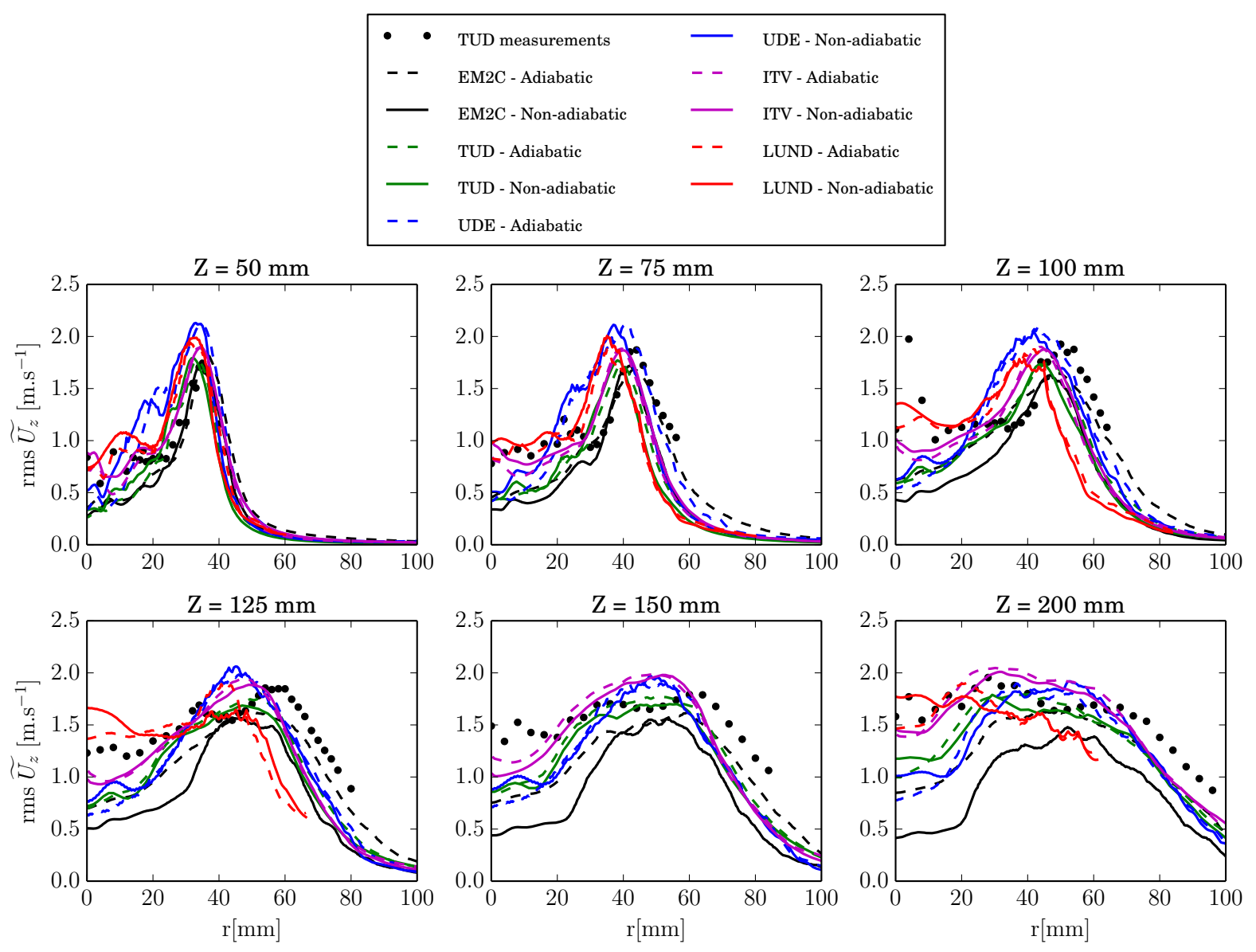

Figure 8: RMS of axial velocity at different axial positions. Solid lines: non-adiabatic LES, dashed lines adiabatic LES. 


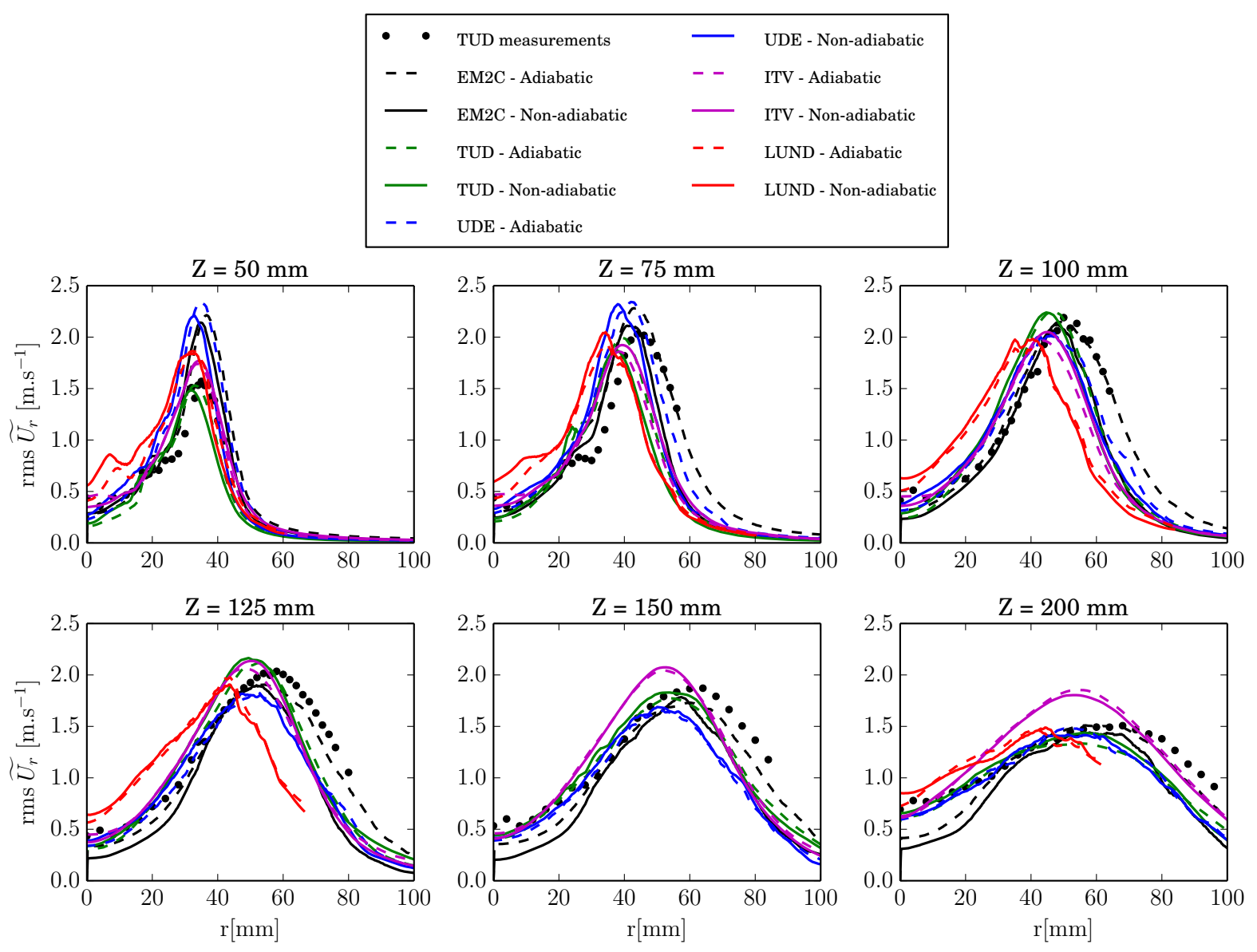

Figure 9: RMS of radial velocity at different axial positions. Solid lines: non-adiabatic LES, dashed lines adiabatic LES. 
ble: the adiabatic LES overestimates the axial velocity because of the under predicted density in the pilot near the centerline. The non-adiabatic simulations show that predictions improve considerably when the heat losses are accounted for. The mean profiles of the radial velocity are hardly affected by the heat loss. The fluctuation levels of the axial and radial velocity components are fairly well predicted by all simulations but tend to be lower for the non-adiabatic cases near the burner, probably due to the lower overall velocity and the lower velocity- and density gradients.

\subsection{Temperature field and flame brush}

The mean temperature field is shown for both adiabatic and non-adiabatic simulations in Figs. 10 and 11, respectively. The influence of heat losses on the temperature field in non-adiabatic simulations is observed by all groups: the reaction products are cooled at the pilot wall and convected downstream, which affects the temperature prediction near the centreline even downstream. These $2 \mathrm{D}$ visualisations do not show pronounced differences between the simulations. The good agreement is confirmed by Figs. 12 and 13, where the mean flame brush positions are shown as mean temperature iso-lines at $1250 \mathrm{~K}$. It is interesting to see that the mean flame brush position is not very sensitive to the different laminar consumption speeds shown in section 2.6.1, although the uncertainty induced by other features of the simulations will tend to attenuate the impact of any specific parameter uncertainty. Slight differences in the prediction of the flame front position are however observed: 


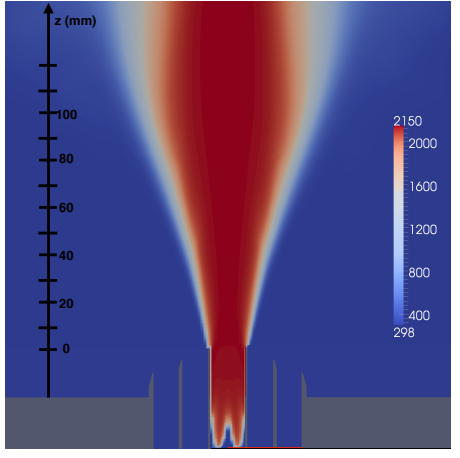

(a) TUD

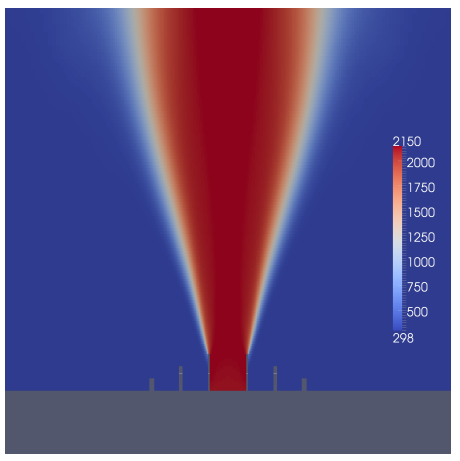

(c) ITV

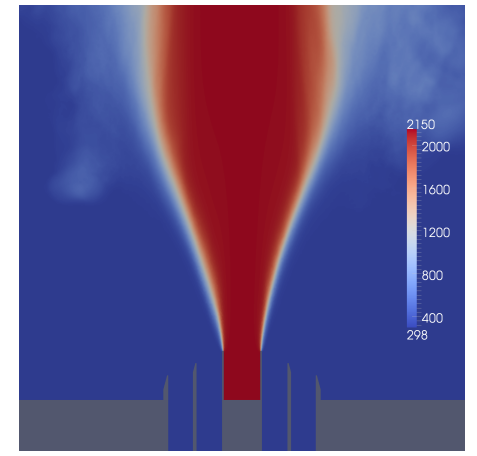

(b) $\mathrm{EM} 2 \mathrm{C}$

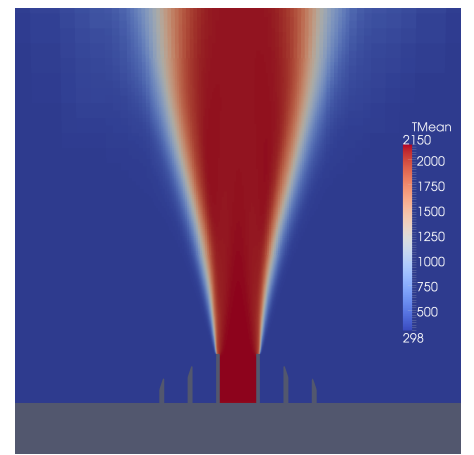

(d) LUND

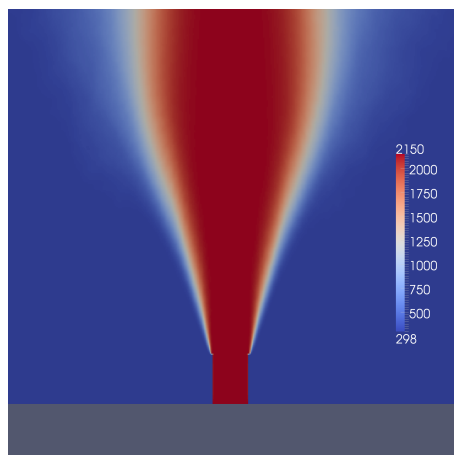

(e) UDE

Figure 10: 2-D iso-contours of the mean flame temperature for the adiabatic simulations 


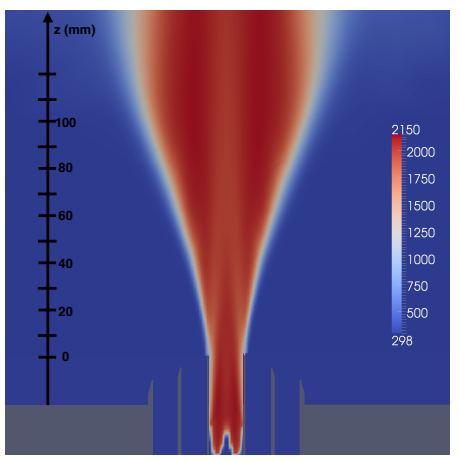

(a) TUD

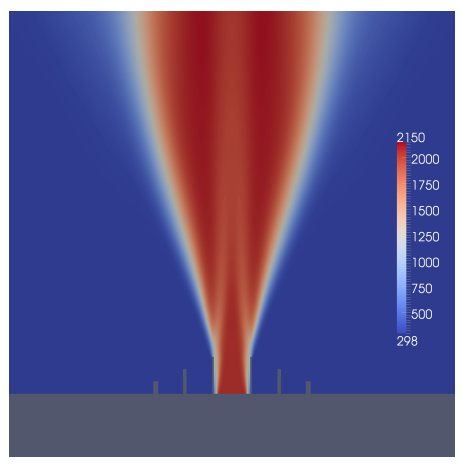

(c) ITV

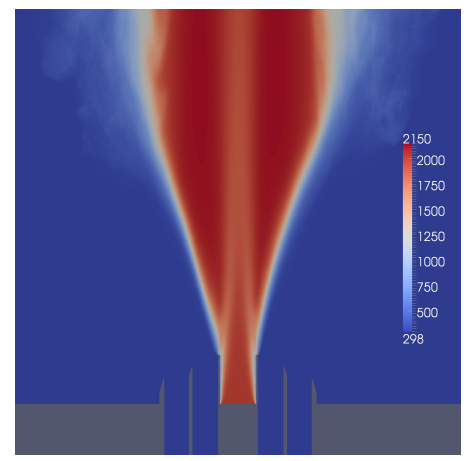

(b) EM2C

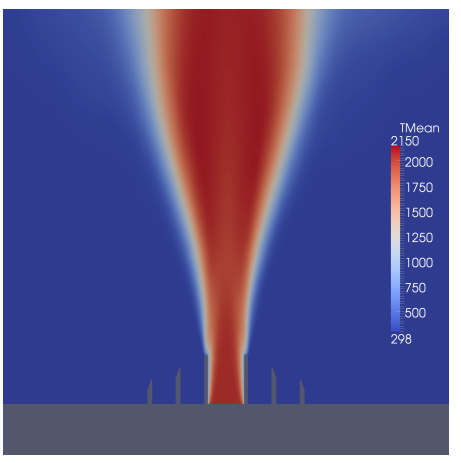

(d) LUND

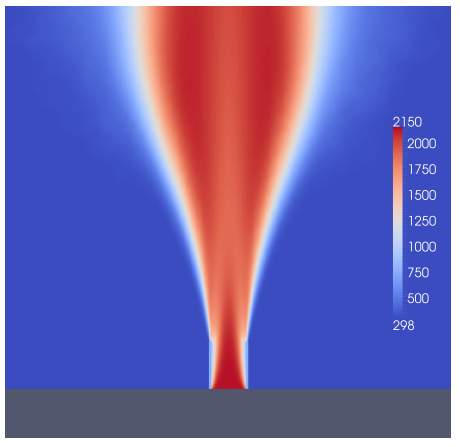

(e) UDE

Figure 11: 2-D iso-contours of the mean flame temperature for the non-adiabatic simulations 


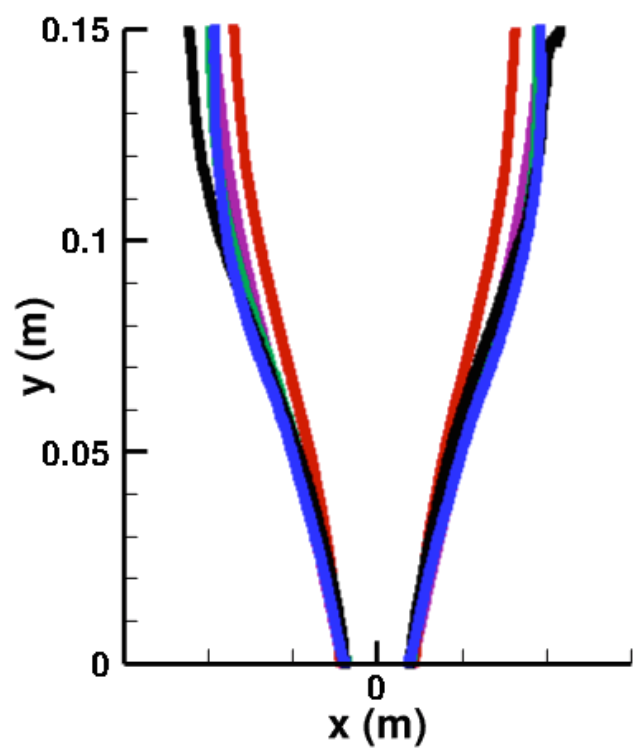

Figure 12: Iso-line of mean temperature $(1250 \mathrm{~K})$ for the adiabatic simulations. Green: TUD; Black: EM2C; Purple: ITV; Red: LUND; Blue: UDE. 


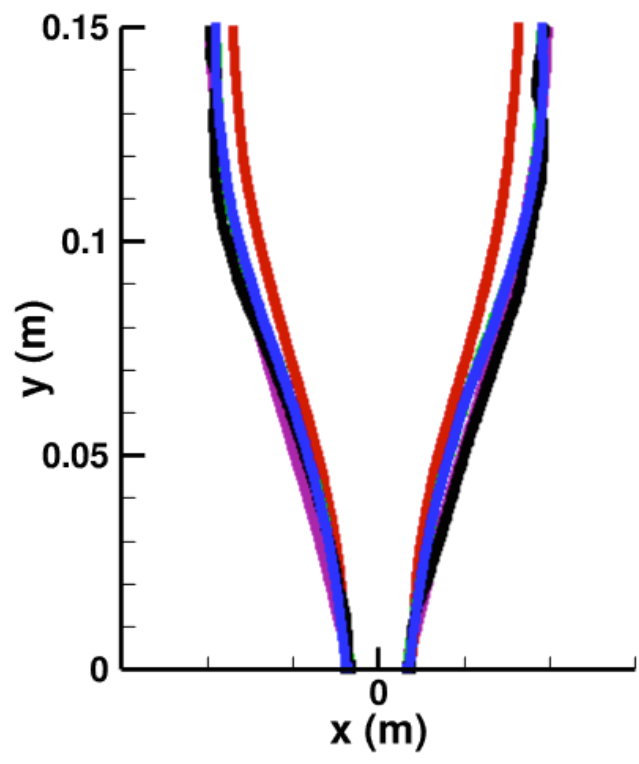

Figure 13: Iso-line of mean temperature (1250K) for the non-adiabatic simulations. Green: TUD; Black: EM2C; Purple: ITV; Red: LUND; Blue: UDE. 


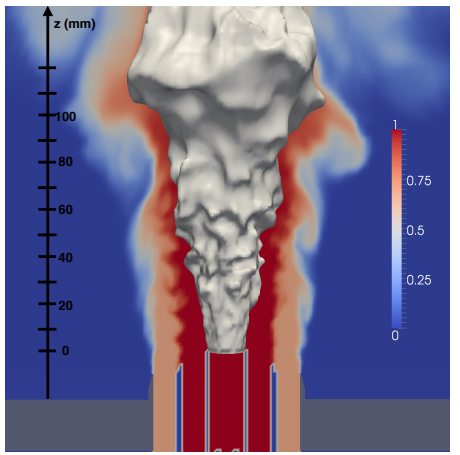

(a) TUD

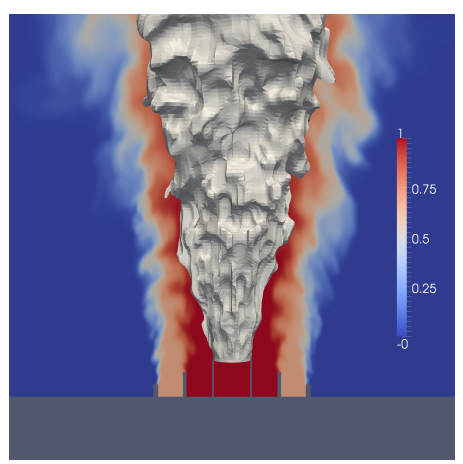

(c) ITV

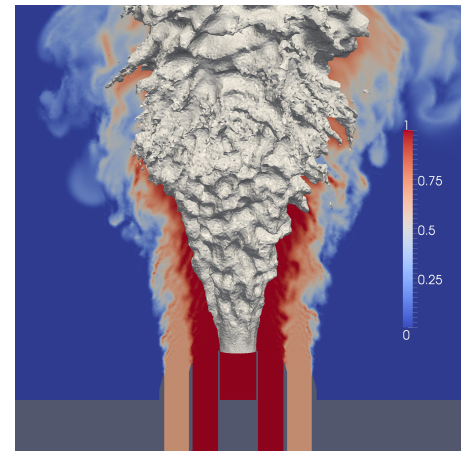

(b) EM2C

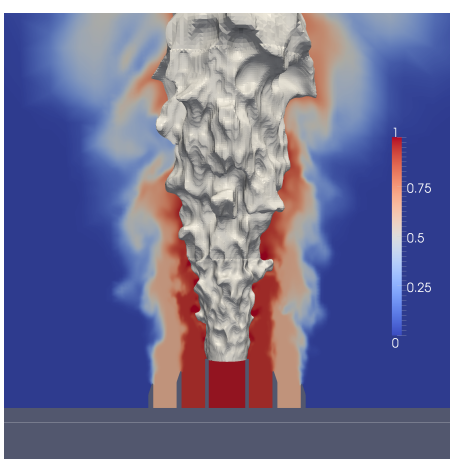

(d) LUND

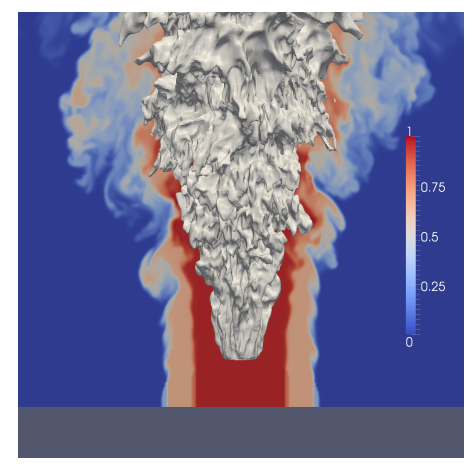

(e) UDE

Figure 14: Instantaneous snapshots from adiabatic simulations of the TSFA flame: 3-D view of $1850 \mathrm{~K}$ temperature iso-surface conditioned on the flame surface. 2D fields shows the mixture fractions iso-contours 


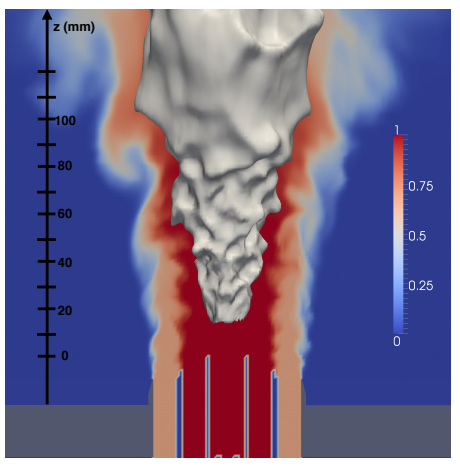

(a) TUD

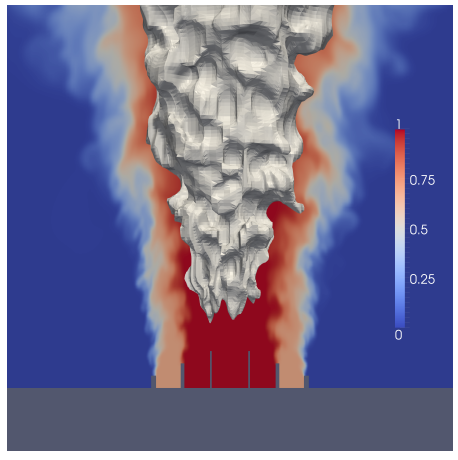

(c) ITV

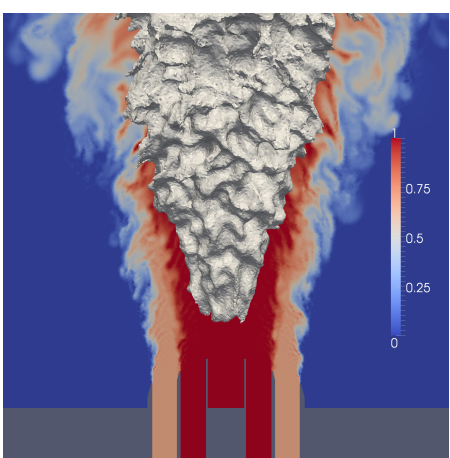

(b) $\mathrm{EM} 2 \mathrm{C}$

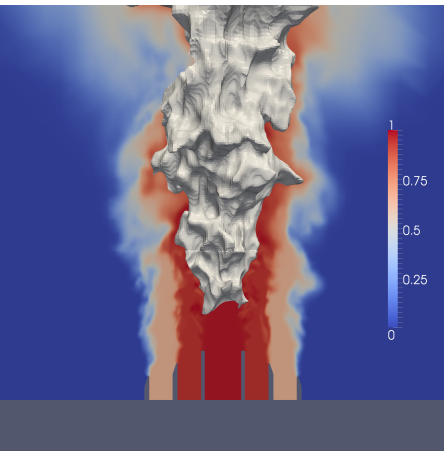

(d) LUND

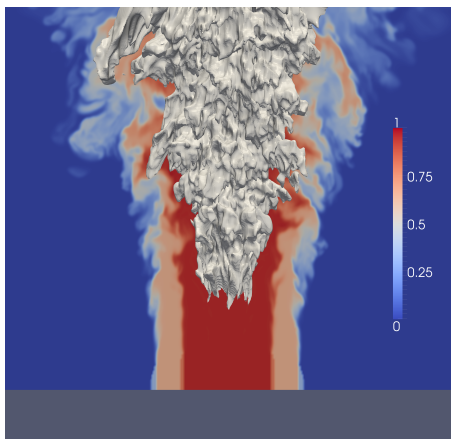

(e) UDE

Figure 15: Instantaneous snapshots from non-adiabatic simulations of the TSFA flame: 3 -D view of $1850 \mathrm{~K}$ temperature iso-surface conditioned on the flame surface. 2D fields shows the mixture fractions iso-contours 


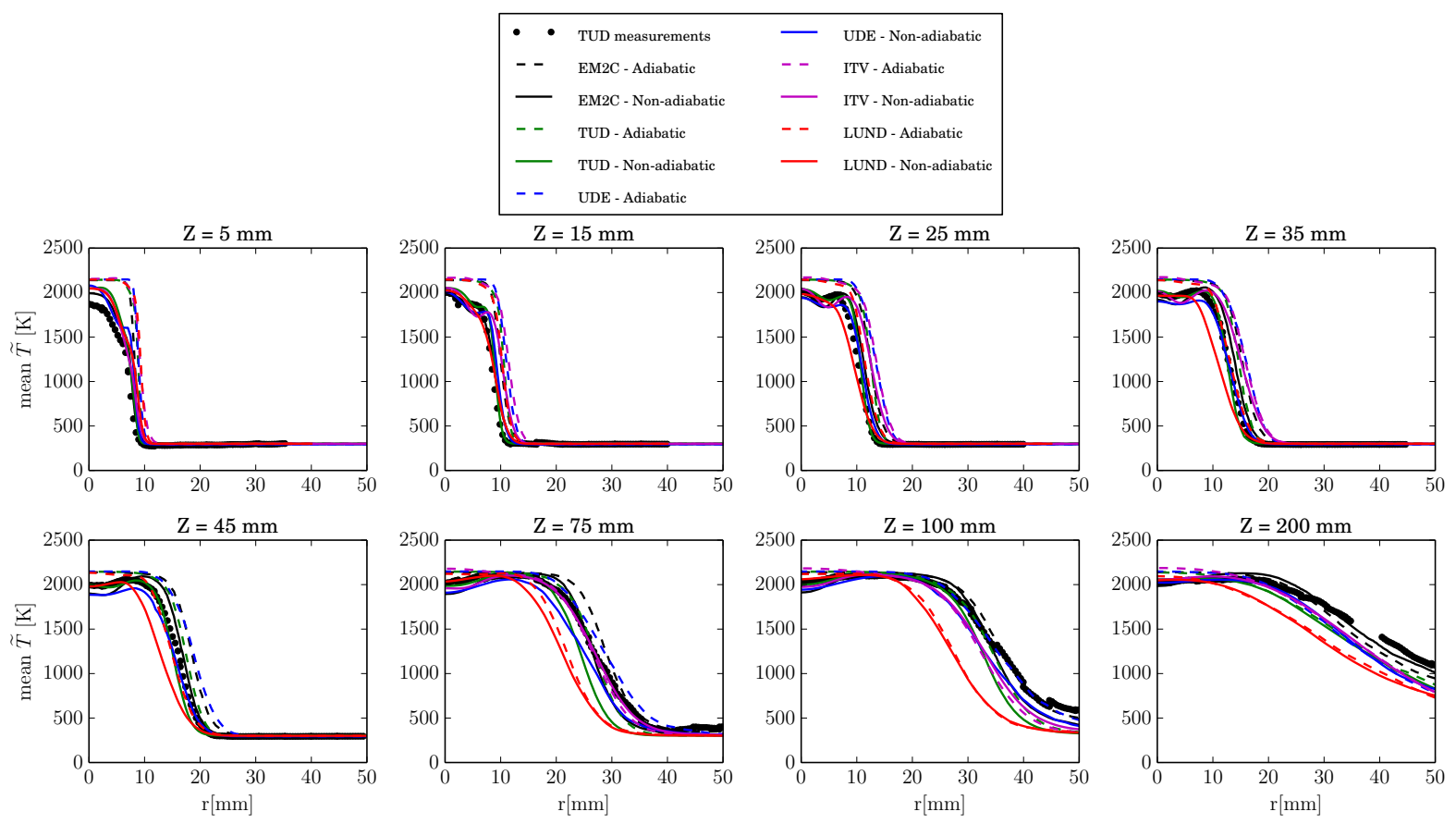

Figure 16: Mean temperature at different axial positions. Solid lines: non-adiabatic LES, dashed lines adiabatic LES. 


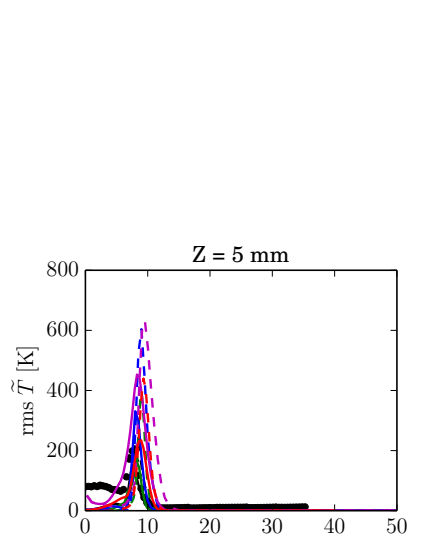

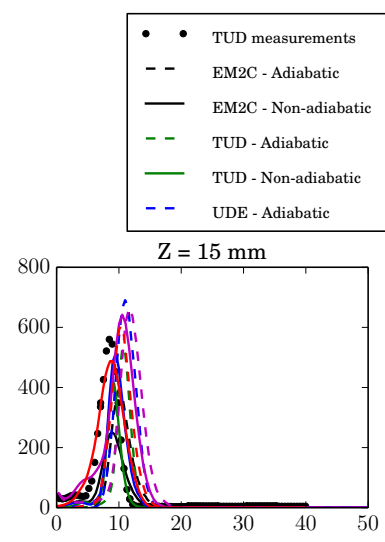

\begin{tabular}{cl}
- & UDE - Non-adiabatic \\
-- & ITV - Adiabatic \\
- & ITV - Non-adiabatic \\
-- & LUND - Adiabatic \\
$-\quad$ & LUND - Non-adiabatic \\
& \\
\hline & $\mathrm{Z}=25 \mathrm{~mm}$
\end{tabular}
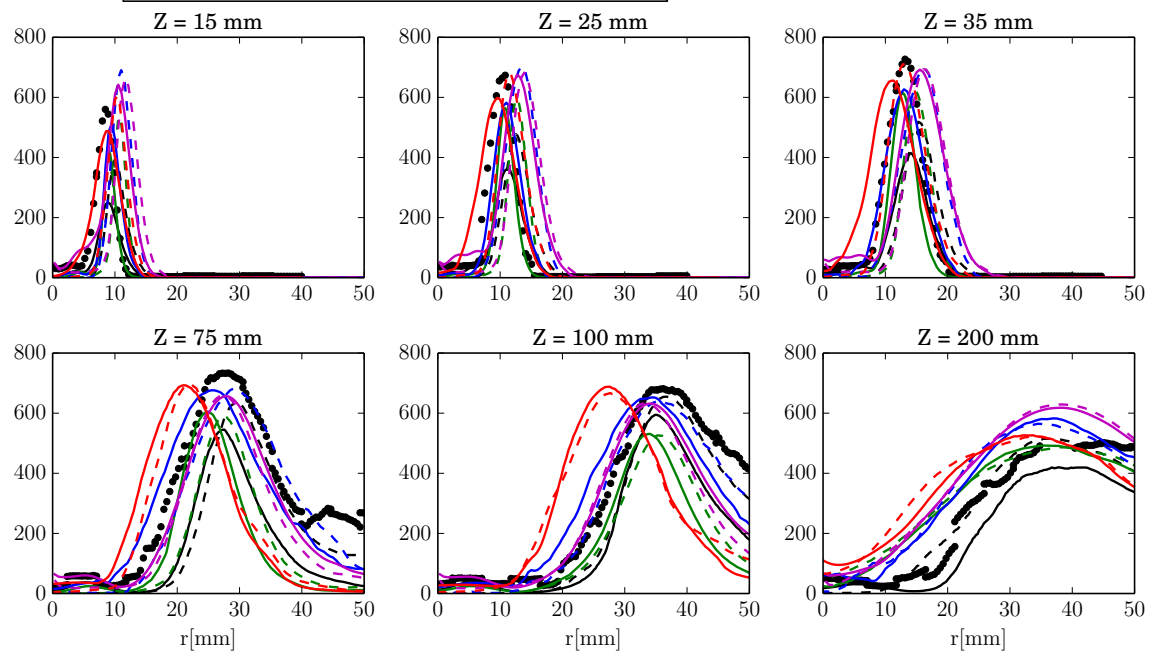

Figure 17: RMS of temperature at different axial positions. Solid lines: non-adiabatic LES, dashed lines adiabatic LES. 
in particular the LUND simulation exhibits the least flame expansion, specially in the downstream flame region, where the grid becomes insufficient to capture both the flame thickness and the flame wrinkling. Both flame under-resolution and the absence of SGS flame wrinkling model in the NCM underestimate the heat release integral across the flame front. This leads to an underestimation of the flame burning velocity and to a lower flame expansion - in spite of the highest laminar flame speed calculated from the 4-step mechanism used by LUND.

As shown in the mean temperature fields (Fig. 11), considering heat loss causes a significant drop in enthalpy near the burner. This affects combustion chemistry and leads to local flame extinction. As all models predict a decrease of the flame consumption speed at the pilot tube, all non-adiabatic computations predict flame lift-off. This is visible in Figs. 14 and 15, which show instantaneous snapshots of the flame front position for both adiabatic and non-adiabatic simulations. The $3-\mathrm{D}$ views of the $1850 \mathrm{~K}$ temperature iso-surface conditioned on the flame surface are also shown. All adiabatic simulations result in a flame anchored at the burner lips, whereas non-adiabatic computations predict a lifted flame. The lift-off height is here defined as the distance between the pilot burner exit and the leading edge of the mean temperature iso-level at $1850 \mathrm{~K}$, protruding into the fresh gas stream. The computed lift-off heights are given in Tab. 6, showing a relatively close agreement observed between the simulations, with a relative difference of $18 \%$.

Means and fluctuations of temperature are compared in Fig. 16. All adi- 
abatic simulations overestimate the measured temperature of the jet at $\mathrm{z}=$ $5 \mathrm{~mm}$ and $\mathrm{z}=15 \mathrm{~mm}$. The non-adiabatic simulations capture the cooling of the pilot tube boundary layer and significantly improve temperature prediction. The flame lift-off in the non-adiabatic simulations induces a shift in of the temperature profiles towards the centreline. In spite of the good agreement in predicted lift-off height, the influence of the lift-off on the mean flame brush position differs between the groups. The NCM (LUND) simulations agree less well downstream, where the flame has been affected most by turbulence. As discussed previously, these discrepancies may partially be attributed to the mesh resolution which is decreased at $z=40 \mathrm{~mm}\left(\Delta_{x}\right.$ is doubled). The absence of SGS turbulent combustion model and flame front resolution treatment become questionable.

At $z=200 \mathrm{~mm}$, there seems to be a correlation between deviations in the predicted mean axial velocity (shown in Fig.6) and in the predicted mean temperature (see Fig. 16). This correlation is a consequence of the link between the velocity field and the mean flame front position [49], as the flame is shifted by the velocity field on the one hand, and dilatation alters the velocity field on the other.

The resolved temperature fluctuations are shown in Fig.17. When interpreting these data, one should bear in mind that they do not include the subgrid fluctuations. As the flame resolution and the filter size vary between the simulations, the resolved part and the subrid contributions must differ slightly between the simulations. The peak of the RMS, is located at the 
mean flame brush position, which is shifted in the non-adiabatic simulations. Similar observations can be made for the species mass fractions $\mathrm{CH}_{4}, \mathrm{CO}_{2}$, $\mathrm{H}_{2} \mathrm{O}, \mathrm{N}_{2}$ and $\mathrm{O}_{2}$, of which means and fluctuations are shown in Appendix A. Numerical and experimental profiles of mean and RMS of mixture fraction are compared in Figs. A.26 and A.27, respectively. As mentioned in [21], unphysical values are detected in the experiments close to the centerline, causing an overestimation of the mixture fraction. Note also that the slight deviations in the mean mixture fraction observed in the LUND model between the pilot and stream one at the burner exit $(\mathrm{z}=5 \mathrm{~mm})$ is due to NCM assumptions.

\subsection{Flame shape and wrinkling}

Despite a fair agreement in the predicted means and fluctuations, the simulations show differences in the predicted flame shape. The instantaneous views in Figs. 14 and 15 illustrate the different rates of resolved wrinkling, although the numerical resolutions of the flame front are comparable (see Tab. 4). Table 6 quantifies the resolved flame wrinkling within a volume between axial positions $z=0$ and $z=100 \mathrm{~mm}$, as the ratio between an instantaneous flame surface versus the mean flame surface, both defined by the $\mathrm{T}=1850 \mathrm{~K}$ iso-level. Differences of up to $40 \%$ are observed between the simulations. Where parts of these differences can be attributed to the grid resolution, others may result from the different sub-grid models. Indeed,

other studies [50] have observed that the modeling choices may affect the 
prediction of the flame response in an unsteady environment - which may explain why various flame wrinkling patterns are observed. The instantaneous views also show noticeable differences in the predicted flame front location

- with the NCM simulation (LUND) showing a smaller flame opening. It is however interesting that in spite of the very different amounts of resolved flame wrinkling achieved by the different simulations, a rather similar behavior is predicted - implying that the different computational strategies and sub-grid models work.

\subsection{Computational cost}

The discussion so far focused on the accuracy of the results, neglecting the computational effort. Table 7 provides the computational cost and run-times. It should be noted that these numbers do not support a precise comparison of code performance, since different MPI-implementations, compilers, interconnects and CPU-cores were used - where the performance per core will vary by a factor of three already. It should also be noted that the run-time is sensitive to the type of grid, the number of iterations in the pressure solver, and the local refinement in high velocity regions (CFL-limit), so that the results shown here could easily be altered by an order of magnitude. And yet, some interesting observations can be made.

Comparing unstructured to structured codes, there is no clear trend for computational efficiency. Where unstructured codes are very efficient in RANS with local refinement, the higher algorithmic effort and the small 
time-steps caused by local refinement appear to compensate for much of the theoretical advantage - at least in the present large eddy simulations. The accuracy requirements of LES can be satisfied even on unstructured grids, using high order schemes as demonstrated by the YALES2 code, but at a cost premium over the simpler discretisations as used by LUND. An almost opposite approach is used by UDE, with a grid of cubes (or voxels) that keep the computational effort per cell very small. Without local refinement, UDE must use more cells, which they can afford due to the simpler code, using twenty times more cells at a comparable cost.

The number of cores used by the groups vary by more than two orders of magnitude - from 32 AMD cores to 8000 cores on a BlueGene/Q, which is reflected by the run-time required to accomplish 0.2 seconds of real time: from three weeks on 60 cores to 8 hours on 8000 cores. These data have however to be interpreted with care as the different architectures vary significantly in terms of computational power per core, memory available, etc ... By considering all these elements, the simulation with the shortest wallclock time would have to speed up 140 thousand times to achieve real-time performance, but already runs 70 times faster than the simulation with the longest wall-clock time with the "FASTEST" code, using a 133 times smaller number of cores. 


\section{Conclusion}

Five different cmputational approaches have been applied to a turbulent stratified flame configuration. The objective of the study is to give a state-ofthe-art picture for a set of computational approaches for capturing turbulent flame front propagation with LES. The computational strategies differ by many aspects of numerics, turbulent combustion models and meshing, but as they are designed to capture turbulent flame propagation, similarities are naturally observed between the simulations. All adiabatic computations agreed in the prediction of a flame anchored at the burner lips, whereas a comparable lift off was calculated by the non-adiabatic ones. The computed mean temperature and species concentrations fields gave further evidence that heat loss effects should be considered in calculation of the flame. Using "No Combustion Model (NCM)" was able to predict the correct mean flame position at the base, where the flow is quasi-laminar. However, stronger deviations are introduced further downstream, where turbulence wrinkles the flame on the resolved scales but also on the sub-grid, which is not captured without model. Grid conditions required in the absence of turbulent combustion model are difficult to satisfy in practice over the entire computational domain.

Overall, most simulations have agreed by a good and perhaps unexpected amount. This agreement may create some confidence that most of these modeling approaches are leading in the right direction, albeit with different priorities that reflect in the deviations between the different results. Where 
most model development and testing is conducted in a single paper for a single test-flame, the present compilation of results has enabled us to achieve a comparison between different computational strategies for turbulent flames - which would have hardly been possible without the TNF workshop.

An interesting finding of this study is that good predictions are achieved by combustion models that treat the stratified flame as an ensemble of homogeneous premixed flames of different mixture fractions. Even though the level of stratification investigated here must be considered to be mild, the good results achieved with this approach were not necessarily expected from the outset, giving evidence that mildly stratified flames can be modelled as a premixed flame. It is however open whether this approach will also work for stronger stratification and turbulence levels, which should be investigated in future studies.

\section{Acknowledgment}

We are grateful for the opportunities provided by the TNF workshop (www.sandia.gov/TNF/) and in particular Rob Barlow for initiating the present paper. The work by the EM2C laboratory at Ecole Centrale Paris was supported by the ANR-10-EESI-05 Grant of the French Ministry of Research, with HPC resources from GENCI-CINES and GENCI-IDRIS (Grant 2011-x2011020164). The authors from Technische Universität Darmstadt gratefully acknowledge the financial support by the German Research Foun-

dation (DFG) throug the excellence initiatives Darmstadt Graduate School 
of Excellence Energy Science and Engineering (GSC 1070) and the Graduate School of Computational Engineering (GSC 233 ). The authors affiliated with Lund University thank the Swedish Energy Agency, Energimyndigheten, for its financial support as well as the SNIC allocation program for providing computational resources at LUNARC and HPC2N. The authors from RWTH Aachen University would like to acknowledge the support of the collaborative research center SFB 686, which is funded by the German Research Association (Deutsche Forschungsgemeinschaft (DFG)). The author from Sogang University acknowledges the support by the National Research Foundation of Korea grant funded by the Korea government(MSIP) (No. NRF-2014R1A2A2A01007732). The Duisburg-Essen authors acknowledge the support form the state of North-Rhine-Westphalia and the compute time granted on JUQUEEN at Jülich Supercomputing Centre (JSC), through the John von Neumann Institute for Computing (NIC).

\section{References}

[1] B. Fiorina, D. Veynante, S. Candel, Modeling combustion chemistry in large eddy simulation of turbulent flames, Flow Turbul. Combust. 94 (2015) 3-42.

[2] T. D. Butler, P. J. O'Rourke, A numerical method for two-dimensional unsteady reacting flows., Proceedings of the 16th Symp. (Int.) on Combustion. The Combustion Institute: Pittsburgh, Penn. (1977) 15031515. 
[3] P. O'Rourke, F. Bracco, Two scaling transformations for the numerical computation of multidimensional unsteady laminar flames, Journal of Computational Physics 33 (1979) 185-203.

[4] O. Colin, F. Ducros, D. Veynante, T. Poinsot, A thickened flame model for large eddy simulations of turbulent premixed combustion, Phys. Fluids 12 (7) (2000) 1843-1863.

[5] M. Boileau, G. Staffelbach, B. Cuenot, T. Poinsot, C. Berat, LES of an ignition sequence in a gas turbine engine, Combust. Flame 154 (1-2) (2008) 2-22.

[6] G. Kuenne, A. Ketelheun, J. Janicka, Les modeling of premixed combustion using a thickened flame approach coupled with fgm tabulated chemistry, Combustion and Flame 158 (9) (2011) 1750 - 1767.

[7] A. Ketelheun, G. Kuenne, J. Janicka, Heat transfer modeling in the context of large eddy simulation of premixed combustion with tabulated chemistry., Flow, Turbulence and Combustion 91 (867-893).

[8] M. Boger, D. Veynante, H. Boughanem, A. Trouvé, Direct numerical simulation analysis of flame surface density concept for large eddy simulation of turbulent premixed combustion, in: Twenty-Seventh Symposium (Int.) on Combustion. The Combustion Institute: Pittsburgh, Penn., 1998, pp. $917-925$. 
[9] C. Duwig, Study of a filtered flamelet formulation for large eddy simulation of premixed turbulent flames, Flow Turbul. Combust. 79 (4) (2007) $433-454$.

[10] B. Fiorina, R. Vicquelin, P. Auzillon, N. Darabiha, O. Gicquel, D. Veynante, A filtered tabulated chemistry model for LES of premixed combustion, Combust. Flame 157 (2010) 465-475.

[11] P. Auzillon, O. Gicquel, N. Darabiha, D. Veynante, B. Fiorina, A filtered tabulated chemistry model for les of stratified flames, Combust. Flame 159 (8) (2012) 2704-2717.

[12] R. Mercier, P. Auzillon, V. Moureau, N. Darabiha, O. Gicquel, D. Veynante, B. Fiorina, LES modeling of the impact of heat losses and differential diffusion on turbulent stratified flame: application to the TU Darmstadt stratified flame, Flow Turbul. Combust. 93 (2) (2014) 349381.

[13] N. Peters, Turbulent Combustion, Cambridge University Press, 2000.

[14] S. Menon, W. Jou, Large eddy simulations of combustion instability in an axisymetric ramjet combustor, Combust. Sci. Technol. 75 (1991) $53-72$.

[15] H. Pitsch, L. Duchamp de Lageneste, Large-eddy simulation of premixed turbulent combustion using a level-set approach, Proceedings of the Combustion Institute 29 (2) (2002) 2001-2008. 
[16] H. Pitsch, A consistent level set formulation for large-eddy simulation of premixed turbulent combustion, Combust. Flame 143 (4) (2005) 587598.

[17] V. Moureau, B. Fiorina, H. Pitsch, A level set formulation for premixed combustion les considering the turbulent flame structure, Combust. Flame 156 (4) (2009) 801-812.

[18] C. Duwig, K. Nogenmyr, C. Chan, M. Dunn, Large eddy simulations of a piloted lean premix jet flame using finite-rate chemistry, Combustion Theory and Modelling 15 (4) (2011) 537-568.

[19] C. Duwig, M. J. Dunn, Large eddy simulation of a premixed jet flame stabilized by a vitiated co-flow: Evaluation of auto-ignition tabulated chemistry, Combustion and Flame 160 (12) (2013) 2879-2895.

[20] F. Seffrin, F. Fuest, D. Geyer, A. Dreizler, Flow field studies of a new series of turbulent premixed stratified flames, Combustion and Flame 157 (2) (2010) $384-396$.

[21] G. Kuenne, F. Seffrin, F. Fuest, T. Stahler, A. Ketelheun, D. Geyer, J. Janicka, A. Dreizler, Experimental and numerical analysis of a lean premixed stratified burner using 1d raman/rayleigh scattering and large eddy simulation, combust. Flame 159 (2669-2689).

[22] B. Fiorina, R. Baron, O. Gicquel, D. Thévenin, S. Carpentier, N. Dara- 
biha, Modelling non-adiabatic partially-premixed flames using flame prolongation of ildm, Combust. Theor. Modell. 7 (2003) 449-470.

[23] F. Charlette, C. Meneveau, D. Veynante, A power-law flame wrinkling model for les of premixed turbulent combustion, part i: non-dynamic formulation, Combust. Flame 131 (1/2) (2002) 159-180.

[24] J. A. van Oijen, L. P. H. de Goey, Modelling of premixed laminar flames using flamelet-generated manifolds., Comb. Sci. and Tech. 1 (161) (2000) 113-137.

[25] P. Trisjono, K. Kleinheinz, H. Pitsch, S. Kang, Large eddy simulation of stratified and sheared flames of a premixed turbulent stratified flame burner using a flamelet model with heat loss, Flow, Turbulence and Combustion 92 (1-2) (2014) 201-235.

[26] E. Knudsen, S. H. Kim, H. Pitsch, An analysis of premixed flamelet models for large eddy simulation of turbulent combustion, Physics of Fluids 22 (11) (2010) 1-24.

[27] G. P. Smith, D. M. Golden, M. Frenklach, N. W. Moriarty, B. Eiteneer, M. Goldenberg, C. T. Bowman, R. K. Hanson, S. Song, W. C. Gardiner, V. V. Lissianski, Z. Qin, http://www.me.berkeley.edu/gri-mech/.

[28] F. Proch, A. Kempf, Modeling heat loss effects in the large eddy simulation of a model gas turbine combustor with premixed flamelet gen- 
erated manifolds, Proceedings of the Combustion Institute (2014) doi:http://dx.doi.org/10.1016/j.proci.2014.07.036.

[29] C. Fureby, A fractal flame-wrinkling large eddy simulation model for premixed turbulent combustion, Proc. Combust. Inst. 30 (2005) 593601.

[30] T. Ma, O. Stein, N. Chakraborty, A. M. Kempf, A-posteriori testing of Algebraic Flame Surface Density models for LES, Combust. Theory Model. 17 (3) (2013) 431-482.

[31] F. C. Marincola, T. Ma, A. Kempf, Large eddy simulations of the darmstadt turbulent stratified flame series, Proceedings of the Combustion Institute 34 (1) (2013) $1307-1315$.

[32] F. Grinstein, K. Kailasanath, Three-dimensional numerical simulations of unsteady reactive square jets, Combustion and Flame 100 (1995) 210.

[33] I. A. Dodoulas, S. Navarro-Martinez, Large eddy simulation of premixed turbulent flames using the probability density function approach, Flow, Turbulence and Combustion 90 (2013) 645-678.

[34] C. Duwig, S. Ducruix, D. Veynante, Studying the stabilization dynamics of swirling partially premixed flames by proper orthogonal decomposition, Journal of Engineering for Gas Turbines and Power 134 (2012) 101501. 
[35] B. Fiorina, O. Gicquel, L. Vervisch, S. Carpentier, N. Darabiha, Approximating the chemical structure of partially-premixed and diffusion counterflow flames using fpi flamelet tabulation, Combust. Flame 140 (3) (2005) 147-160.

[36] P. Lindstedt, 12 month progree report 1., Tech. rep., Brite Euram Program Project BE 95 1523, report No. TR-96 009 (1997).

[37] N. Peters, B. Rogg, Reduced Kinetic Mechanisms for Applications in Combustion Systems., Springer-Verlag, New YorkVerlag, 1993.

[38] W. Jones, R. Lindstedt, Global reaction schemes for hydrocarbon combustion, Combustion and Flame 73 (3) (1988) 233-249.

[39] Y. Dong, C. M. Vagelopoulos, G. R. Spedding, F. N. Egolfopoulos, Measurement of laminar flame speeds through digital particle image velocimetry: mixture of methane and ethane with hydrogen, oxygen, nitrogen and helium, Proc. Combust. Inst. 29 (2002) 1419-1426.

[40] F. Proch, A. M. Kempf, Numerical analysis of the cambridge stratified flame series using artificial thickened flame LES with tabulated premixed flame chemistry, Combustion and Flame 161 (10) (2014) 2627 - 2646.

[41] N. Peters, The turbulent burning velocity for large-scale and small-scale turbulence, Journal of Fluid mechanics 384 (1999) 107-132.

[42] T. Lehnhauser, M. Schafer, Improved linear interpolation practice for 
finite-volume schemes on complex grids, Int. J. Numer. Methods Fluids (625-645).

[43] G. Zhou, L. Davidson, E. Olsson, Transonic inviscid/turbulent airfoil flow simulations using a pressure based method with high order schemes, in: Fourteenth International Conference on Numerical Methods in Fluid Dynamics. Lecture notes in physics, Vol. 453, 1995, pp. 372-378.

[44] M. Germano, U. Piomelli, P. Moin, W. Cabot, A dynamic subgrid-scale eddy viscosity model, Phys. Fluids A 3 (7) (1991) 1760-1765.

[45] V. Moureau, P. Domingo, L. Vervisch, From large-eddy simulation to direct numerical simulation of a lean premixed swirl flame: Filtered laminar flame-pdf, Combust. Flame 158 (7) (2011) 1340-1357.

[46] M. Kraushaar, Application of the compressible and low mach number approaches to large eddy simulations of turbulent flows in aero-engines, Ph.D. thesis, Institut National Polytechnique de Toulouse (2011).

[47] F. Ducros, F. Nicoud, T. Poinsot, Wall-adapting local eddy-viscosity models for simulations in complex geometries., in: E. B. M. J. (Ed.), In ICFD, 1998, pp. pp. 293-300.

[48] J. Smagorinsky, General circulation experiments with the primitives equations, Mon. Weather Rev. 61 (1963) 99-164.

[49] T. Poinsot, D. Veynante, Theoretical and Numerical Combustion, R. T. Edwards, Inc., 2005. 
[50] P. Auzillon, B. Fiorina, R. Vicquelin, N. Darabiha, O. Gicquel, D. Veynante, Modeling chemical flame structure and combustion dynamics in les, Proc. Combust. Inst. 3333 (1) (2011) 1331-1338. 


\begin{tabular}{|c|c|c|c|c|}
\hline $\begin{array}{c}\text { Simulation } \\
\text { number } \\
\end{array}$ & $\begin{array}{c}\text { Computational } \\
\text { domain } \\
\end{array}$ & $\begin{array}{l}\text { Number of } \\
\text { control vol. }\end{array}$ & $\begin{array}{l}\text { Flame resolution } \\
\qquad \Delta_{x} / \delta_{l} \\
\end{array}$ & $\begin{array}{c}\text { Combustion } \\
\text { model } \\
\end{array}$ \\
\hline TUD & $\begin{array}{c}\text { Pilot, slot } 1 \text { and slot } 2: z_{-}=-120 \mathrm{~mm} \\
\text { Coflow: } z_{-}=-40 \mathrm{~mm} \\
\text { Outlet: } z_{+}=600 \mathrm{~mm}\end{array}$ & $6.5 \mathrm{M}$ & $0.4-4.4$ & $\begin{array}{l}\text { ATF-FGM } \\
(2<\mathrm{F}<15)\end{array}$ \\
\hline EM2C & $\begin{array}{l}\text { Slot } 1 \text { and slot } 2: z_{-}=-120 \mathrm{~mm} \\
\text { Coflow and pilot: } z_{-}=-20 \mathrm{~mm} \\
\quad \text { Outlet: } z_{+}=1100 \mathrm{~mm}\end{array}$ & $5.4 \mathrm{M}$ & 3 & $\begin{array}{l}\text { F-TACLES } \\
\left(\Delta=10 \delta_{l}\right)\end{array}$ \\
\hline ITV & $\begin{array}{l}\text { Slot } 1 \text { and slot } 2: z_{-}=-15 \mathrm{~mm} \\
\text { Coflow and pilot: } z_{-}=-15 \mathrm{~mm} \\
\text { Outlet: } z_{+}=1100 \mathrm{~mm}\end{array}$ & $3.1 \mathrm{M}$ & 2.3 & $\begin{array}{l}\text { Coupled } \\
\text { G-eq / C }\end{array}$ \\
\hline LUND & $\begin{array}{c}\text { Pilot, coflow: } z_{-}=-20 \mathrm{~mm} \\
\text { Slot } 1 \text { and slot } 2:: z_{-}=-20 \mathrm{~mm} \\
\text { Outlet: } z_{+}=1200 \mathrm{~mm}\end{array}$ & $2.9 \mathrm{M}$ & 0.96 & No model \\
\hline UDE & $\begin{array}{c}\text { Pilot, coflow: } z_{-}=-20 \mathrm{~mm} \\
\text { Slot } 1 \text { and slot } 2:: z_{-}=-20 \mathrm{~mm} \\
\text { Outlet: } z_{+}=220 \mathrm{~mm}\end{array}$ & $110 \mathrm{M}$ & 1.0 & FSD \\
\hline
\end{tabular}

Table 4: Computational domain, grid, flame resolution and turbulent combustion model properties. $z_{-}$and $z_{+}$are the axial position of inlet and outlet planes. $\delta_{l}=\left(T^{b}-\right.$ $\left.T^{u}\right) / \operatorname{Max}|\nabla T| \approx 0.5 \mathrm{~mm}$ is an estimation of the thermal flame thickness (for an equivalence ratio $\phi=0.9$, assuming Le $=1$ and using GRI3.0 mechanism [27]). Most important model parameters are indicated. $F$ is the thickening factor of ATF model. $\Delta_{x}$ is the grid size in the flame region. $\Delta$ is the filter width introduced to build the filtered look-up table used in F-TACLES. 


\begin{tabular}{cccc}
\hline \hline $\begin{array}{c}\text { Simulation } \\
\text { type }\end{array}$ & $\begin{array}{c}\text { Pilot inner } \\
\text { wall }\end{array}$ & $\begin{array}{c}\text { Pilot inlet } \\
\text { stream temperature }\end{array}$ & $\begin{array}{c}\text { Pilot } \\
\text { mass flow rate }\end{array}$ \\
\hline \hline $\begin{array}{c}\text { Adiabatic } \\
\text { Non-Adiabatic }\end{array}$ & Adiabatic wall & $2132 \mathrm{~K}$ & $1.952 \times 10^{-4} \mathrm{~kg} / \mathrm{s}$ \\
\hline \hline
\end{tabular}

Table 5: Boundary conditions prescribed by all groups for the pilot inlet stream (except TUD who includes the pilot flame in their computation and did not specify the inlet stream temperature). The pilot mass flow rate has been measured in the experiment [20].

\begin{tabular}{ccc}
\hline \hline Simulation & $\begin{array}{c}\text { Lift-off height } \\
(\mathrm{mm})\end{array}$ & $\begin{array}{c}\text { Resolved flame } \\
\text { wrinkling }\end{array}$ \\
\hline \hline TUD & 15 & 1.4 \\
\hline EM2C & 15 & 1.8 \\
\hline ITV & 17 & 1.8 \\
\hline LUND & 15 & 2.2 \\
\hline DUE & 22 & 3.5 \\
\hline \hline Relative difference & $18 \%$ & $41 \%$
\end{tabular}

Table 6: Flame lift-off height and resolved flame wrinkling for each computation. The flame lift-off height is defined as the distance between the pilot burner exit and the leading edge of the mean temperature iso-level at $1850 \mathrm{~K}$. The resolved flame wrinkling is roughly estimated as the ratio between an instantaneous flame surface versus the mean flame surface (both surfaces are defined at the $\mathrm{T}=1850 \mathrm{~K}$ iso-level). Relative difference corresponds to the ratio between the RMS and the mean value. 


\begin{tabular}{|c|c|c|c|c|c|c|c|c|c|}
\hline $\begin{array}{l}\text { group } \\
\text { code }\end{array}$ & $\begin{array}{l}\text { grid } \\
\text { order }\end{array}$ & $\begin{array}{l}\text { processors } \\
\text { clock rate }\end{array}$ & $\begin{array}{c}N \\
\text { cores }\end{array}$ & $\begin{array}{c}T \\
\text { C-time }\end{array}$ & $\begin{array}{c}t \\
\text { sim-time }\end{array}$ & $\begin{array}{c}n \\
\text { cells }\end{array}$ & $\begin{array}{c}m \\
\text { steps }\end{array}$ & $\begin{array}{l}\text { CFL } \\
T / N\end{array}$ & $\begin{array}{c}T / t \\
T / t / N\end{array}$ \\
\hline- & - & - & 1 & $10^{3} \mathrm{~h}$ & $\mathrm{~s}$ & $10^{6}$ & $10^{3}$ & 1 & $10^{6}$ \\
\hline $\begin{array}{c}\text { TUD } \\
\text { FASTEST }\end{array}$ & $\begin{array}{c}\text { struct. } \\
\mathrm{O}(2)\end{array}$ & $\begin{array}{c}\text { Xeon } 5660 \\
2.8 \mathrm{GHz}\end{array}$ & 60 & 67 & 0.42 & 6.5 & 350 & $\begin{array}{c}0.2 \\
46 \mathrm{~d}\end{array}$ & $\begin{array}{l}580 \\
9.6\end{array}$ \\
\hline $\begin{array}{l}\text { EM2C } \\
\text { YALES2 }\end{array}$ & $\begin{array}{l}\text { unstr. } \\
\mathrm{O}(4)\end{array}$ & $\begin{array}{c}\text { PowerA2 } \\
1.6 \mathrm{GHz}\end{array}$ & 1000 & 200 & 0.20 & 5.4 & 28 & $\begin{array}{l}0.6 \\
8 \mathrm{~d}\end{array}$ & $\begin{array}{c}3600 \\
3.6\end{array}$ \\
\hline $\begin{array}{l}\text { ITV } \\
\text { CIAO }\end{array}$ & $\begin{array}{c}\text { struct. } \\
\mathrm{O}(2)\end{array}$ & $\begin{array}{c}\text { Xeon } 2680 \\
2.7 \mathrm{GHz}\end{array}$ & 48 & 30 & 0.25 & 3.1 & 50 & $\begin{array}{l}0.6 \\
26 \mathrm{~d}\end{array}$ & $\begin{array}{c}540 \\
9\end{array}$ \\
\hline $\begin{array}{c}\text { LUND } \\
\text { OpenFOAM }\end{array}$ & $\begin{array}{l}\text { unstr. } \\
\mathrm{O}(2)\end{array}$ & $\begin{array}{c}\text { AMD } 6220 \\
3.0 \mathrm{GHz}\end{array}$ & 32 & 11 & 0.36 & 3.0 & 140 & $\begin{array}{c}0.1 \\
14 \mathrm{~d}\end{array}$ & $\begin{array}{l}120 \\
3.6\end{array}$ \\
\hline $\begin{array}{l}\text { UDE } \\
\text { PsiPhi }\end{array}$ & $\begin{array}{c}\text { struct. } \\
\mathrm{O}(2)\end{array}$ & $\begin{array}{c}\text { PowerA2 } \\
1.6 \mathrm{GHz}\end{array}$ & 8000 & 360 & 1.10 & 110.0 & 100 & $\begin{array}{l}0.5 \\
2 \mathrm{~d}\end{array}$ & $\begin{array}{l}1200 \\
0.14\end{array}$ \\
\hline
\end{tabular}

Table 7: Overview of the computations. The table shows the research groups, the type of grid and the achieved order of accuracy, the type of processors with its clock rate (Power cores are part of IBM BlueGene/Q systems), the number of cores, the core-hours, the simulated real time, the number of grid cells, the number of iterative steps, the CFL number and approximate run time in days, the ratio of core time to real time and finally the factor between real-time and wall-clock time (or by which factor the simulation needs to be speed up to achieve real time). 
Appendix A. Species mass fractions 


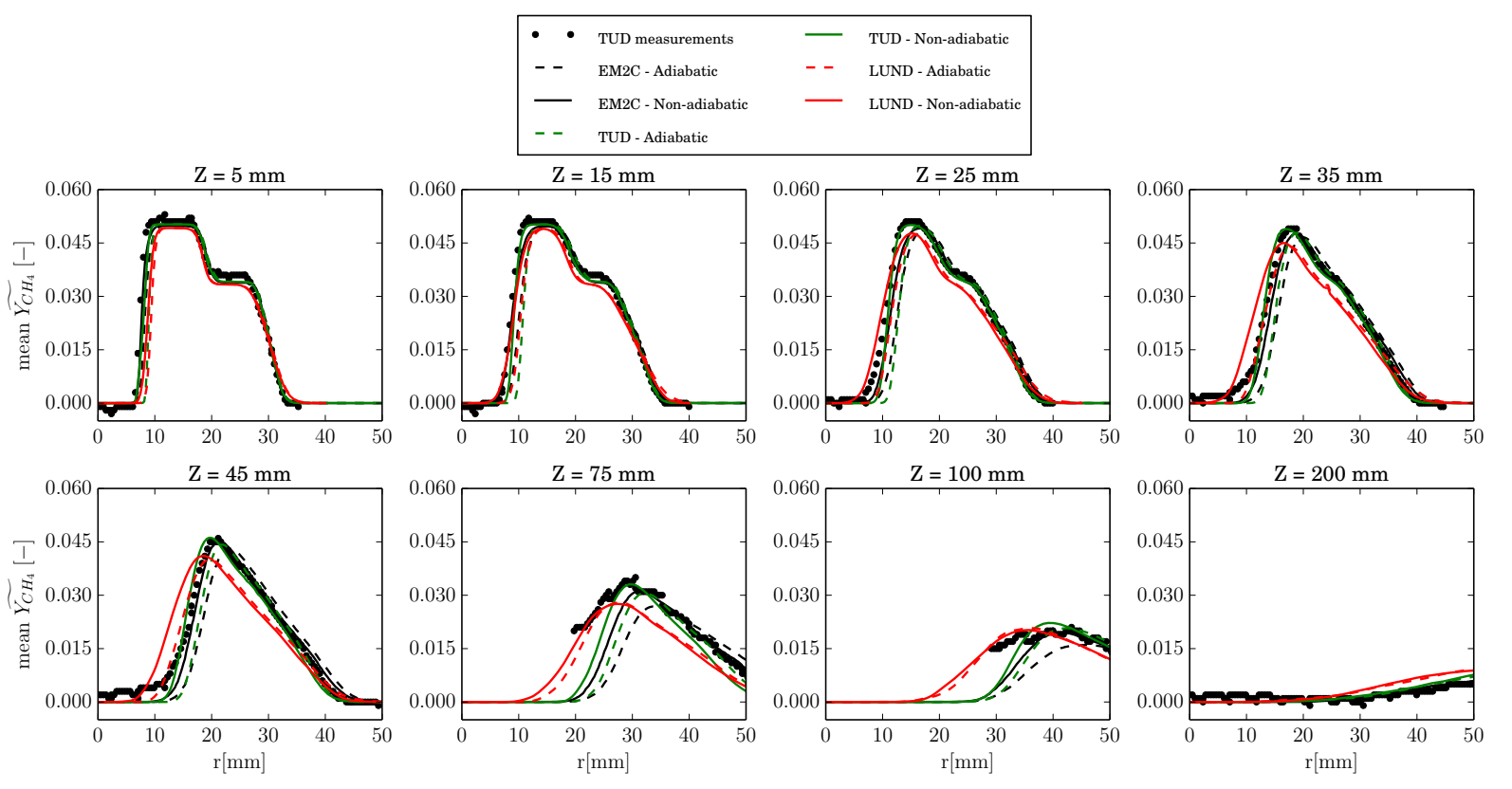

Figure A.18: Mean $\mathrm{CH}_{4}$ mass fraction at different axial positions. Solid lines: nonadiabatic LES, dashed lines adiabatic LES. 

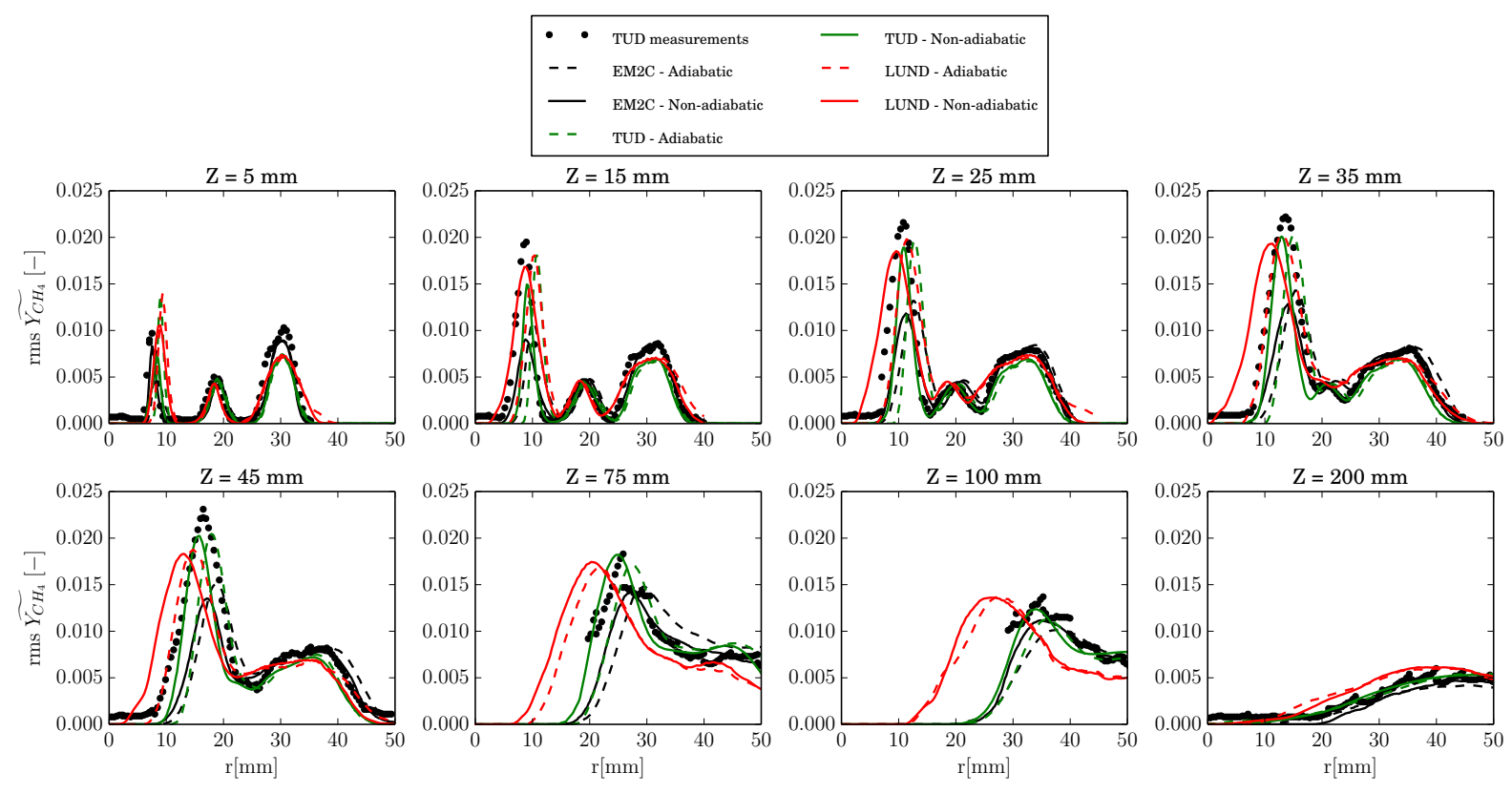

Figure A.19: RMS of $\mathrm{CH}_{4}$ mass fraction at different axial positions. Solid lines: nonadiabatic LES, dashed lines adiabatic LES. 


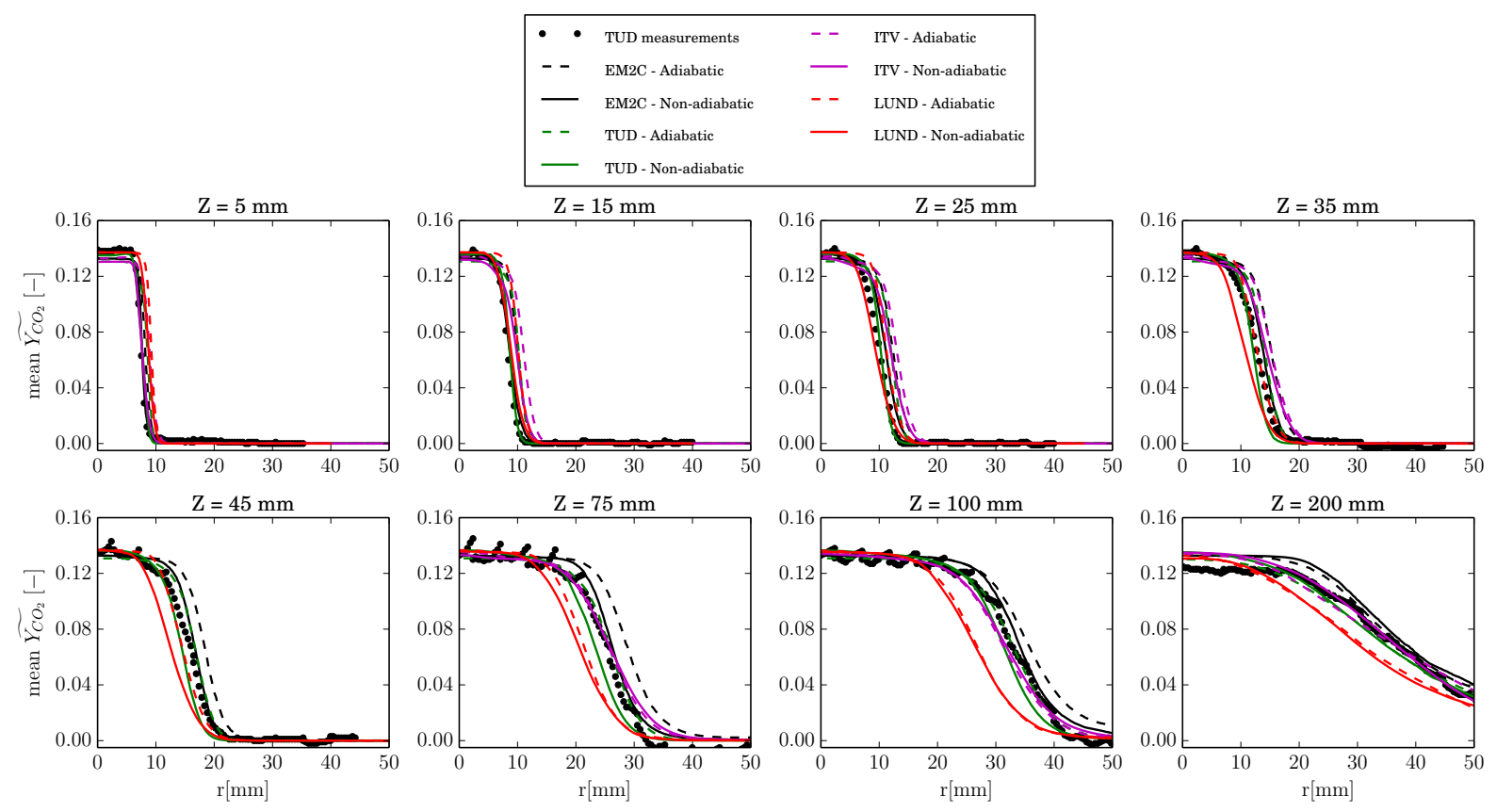

Figure A.20: Mean $\mathrm{CO}_{2}$ mass fraction at different axial positions. Solid lines: nonadiabatic LES, dashed lines adiabatic LES. 


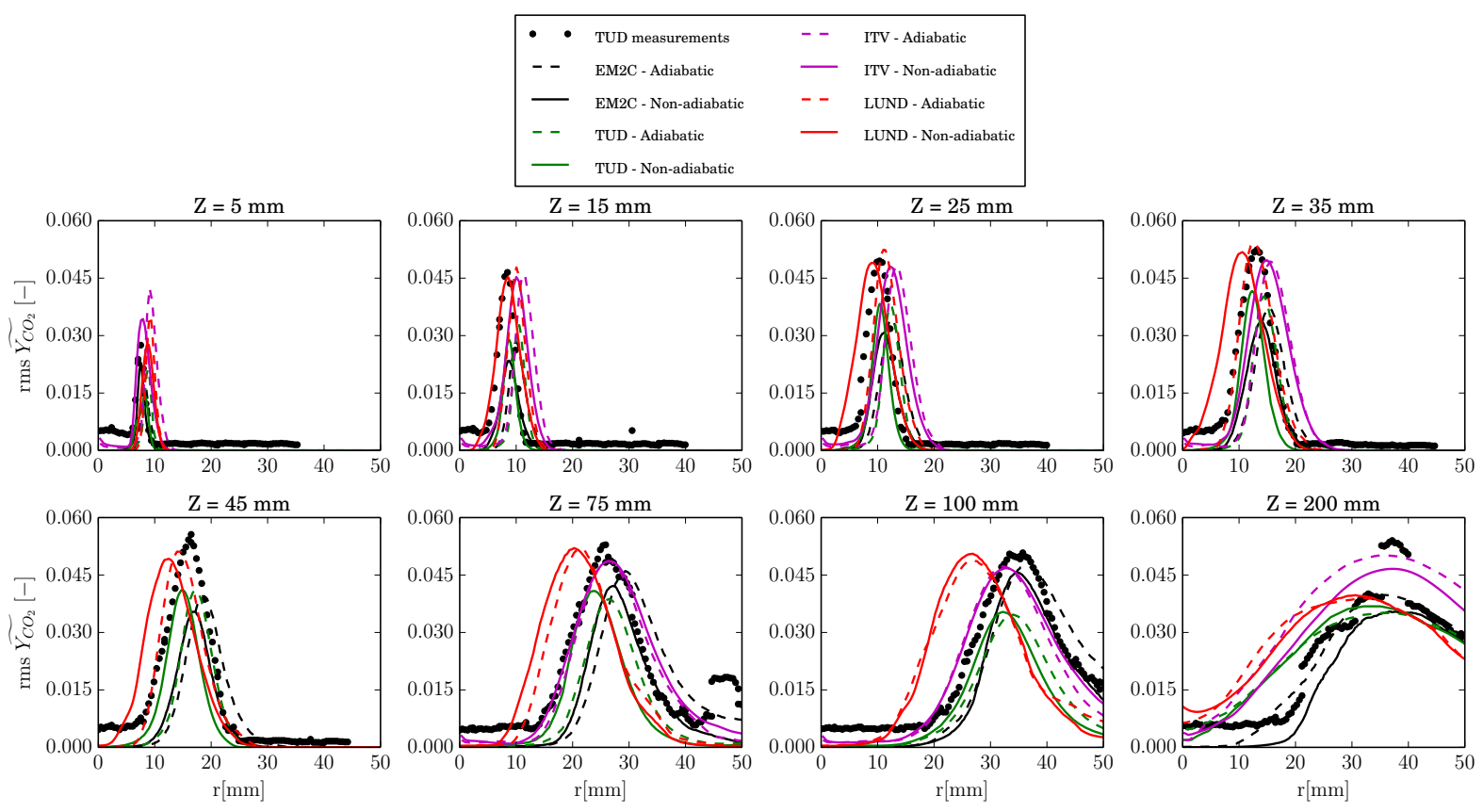

Figure A.21: RMS of $\mathrm{CO}_{2}$ mass fraction at different axial positions. Solid lines: nonadiabatic LES, dashed lines adiabatic LES. 

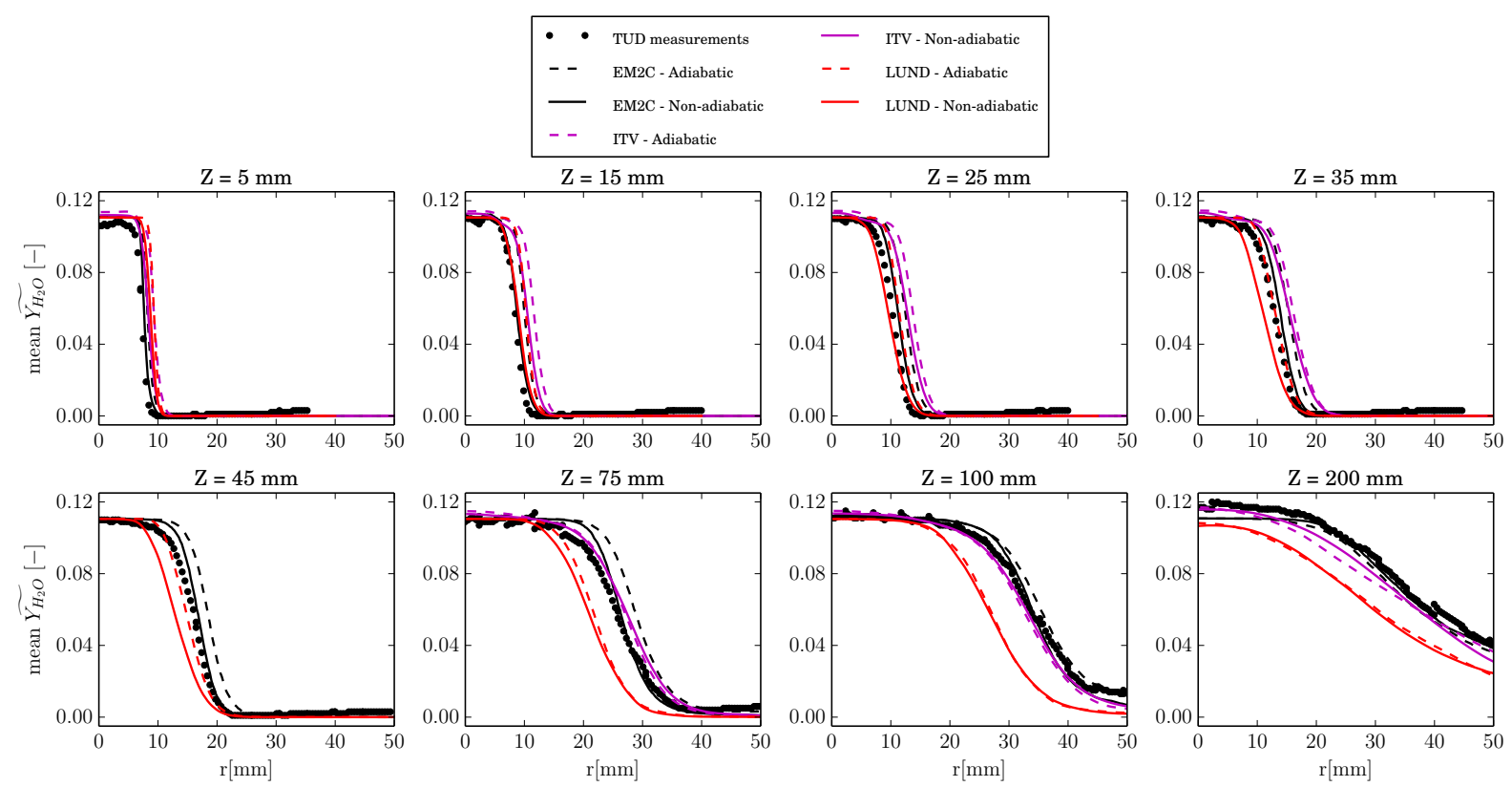

Figure A.22: Mean $\mathrm{H}_{2} \mathrm{O}$ mass fraction at different axial positions. Solid lines: nonadiabatic LES, dashed lines adiabatic LES. 

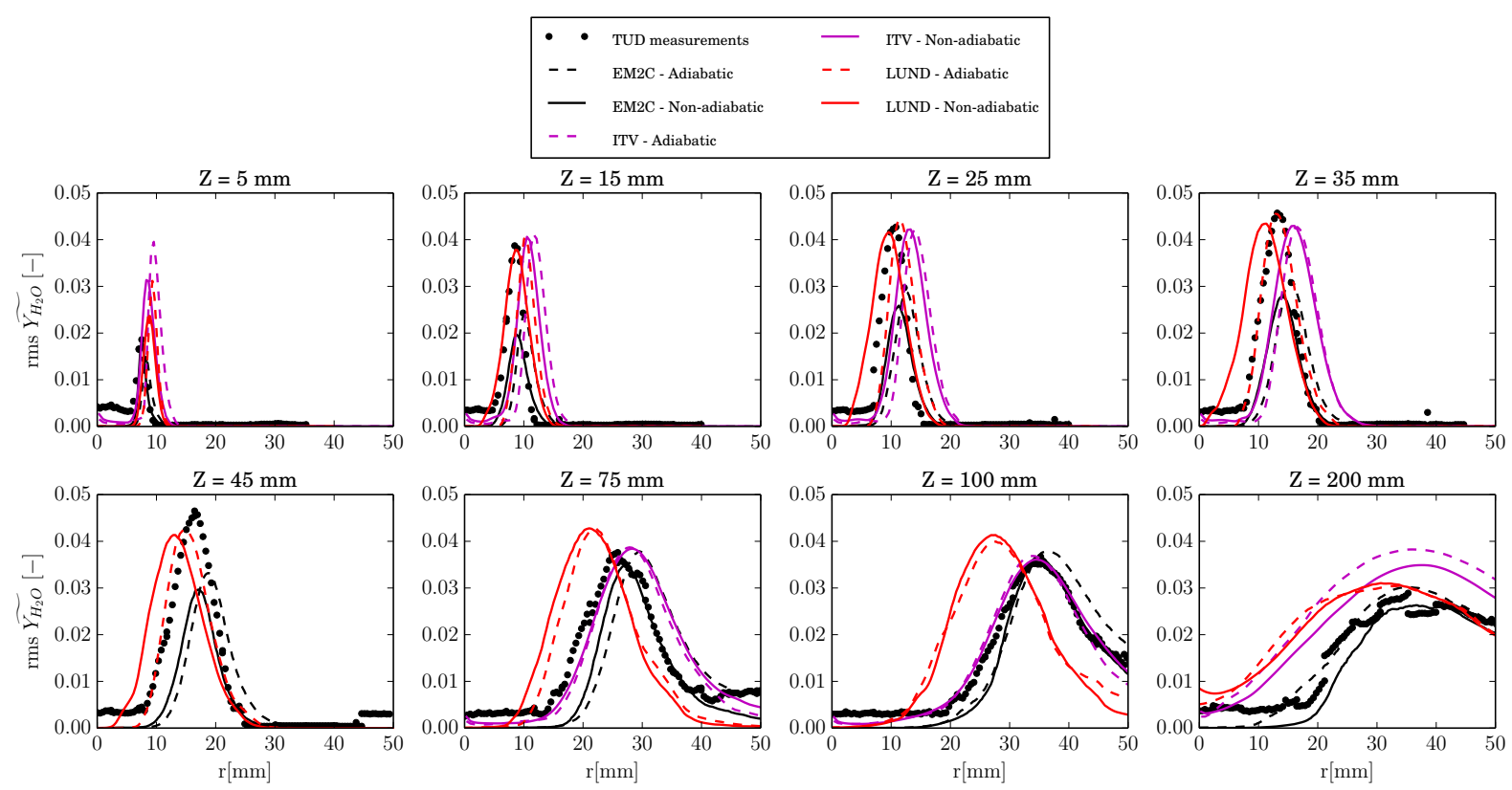

Figure A.23: RMS of $\mathrm{H}_{2} \mathrm{O}$ mass fraction at different axial positions. Solid lines: nonadiabatic LES, dashed lines adiabatic LES. 


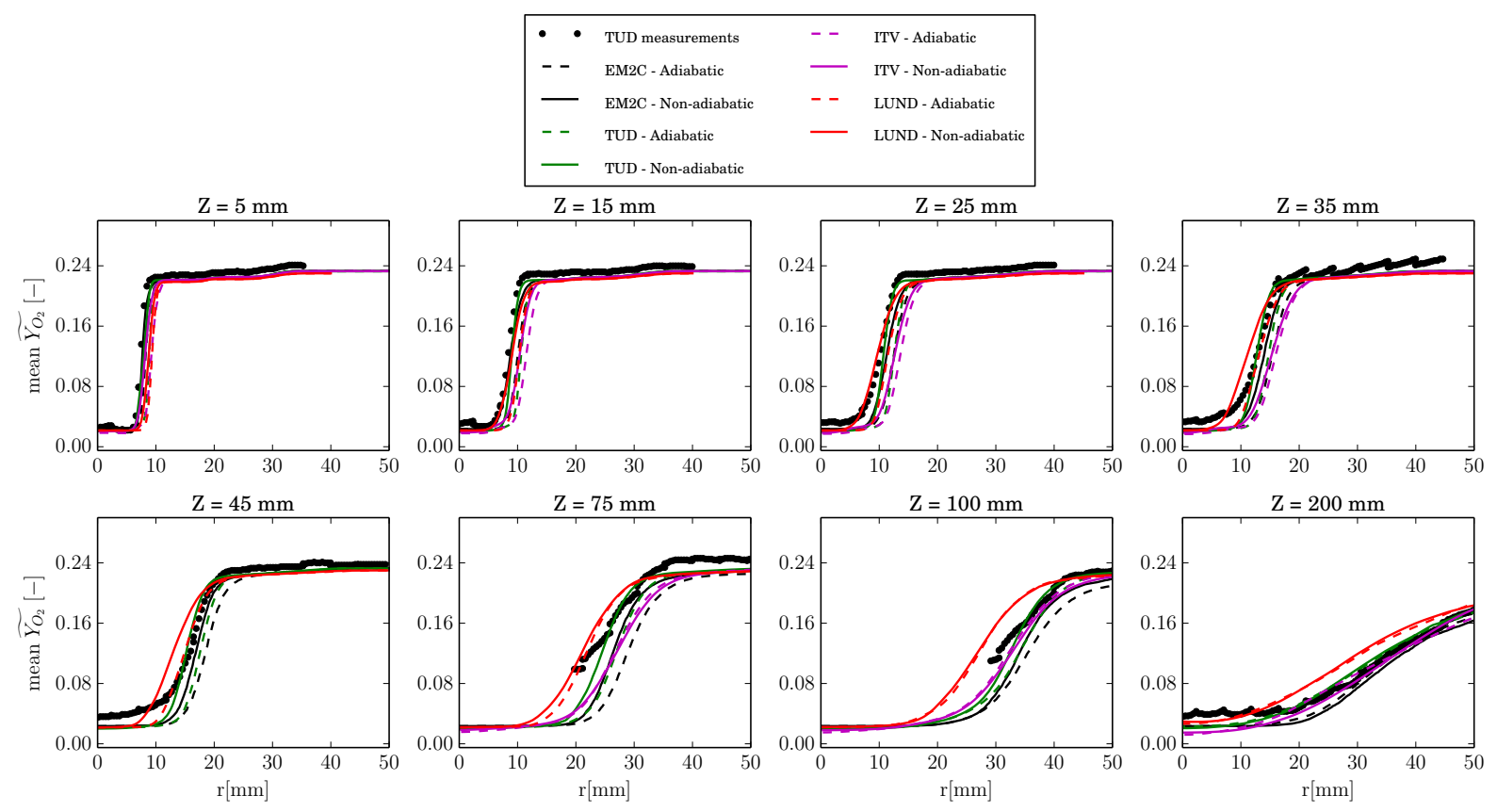

Figure A.24: Mean $\mathrm{O}_{2}$ mass fraction at different axial positions. Solid lines: non-adiabatic LES, dashed lines adiabatic LES. 


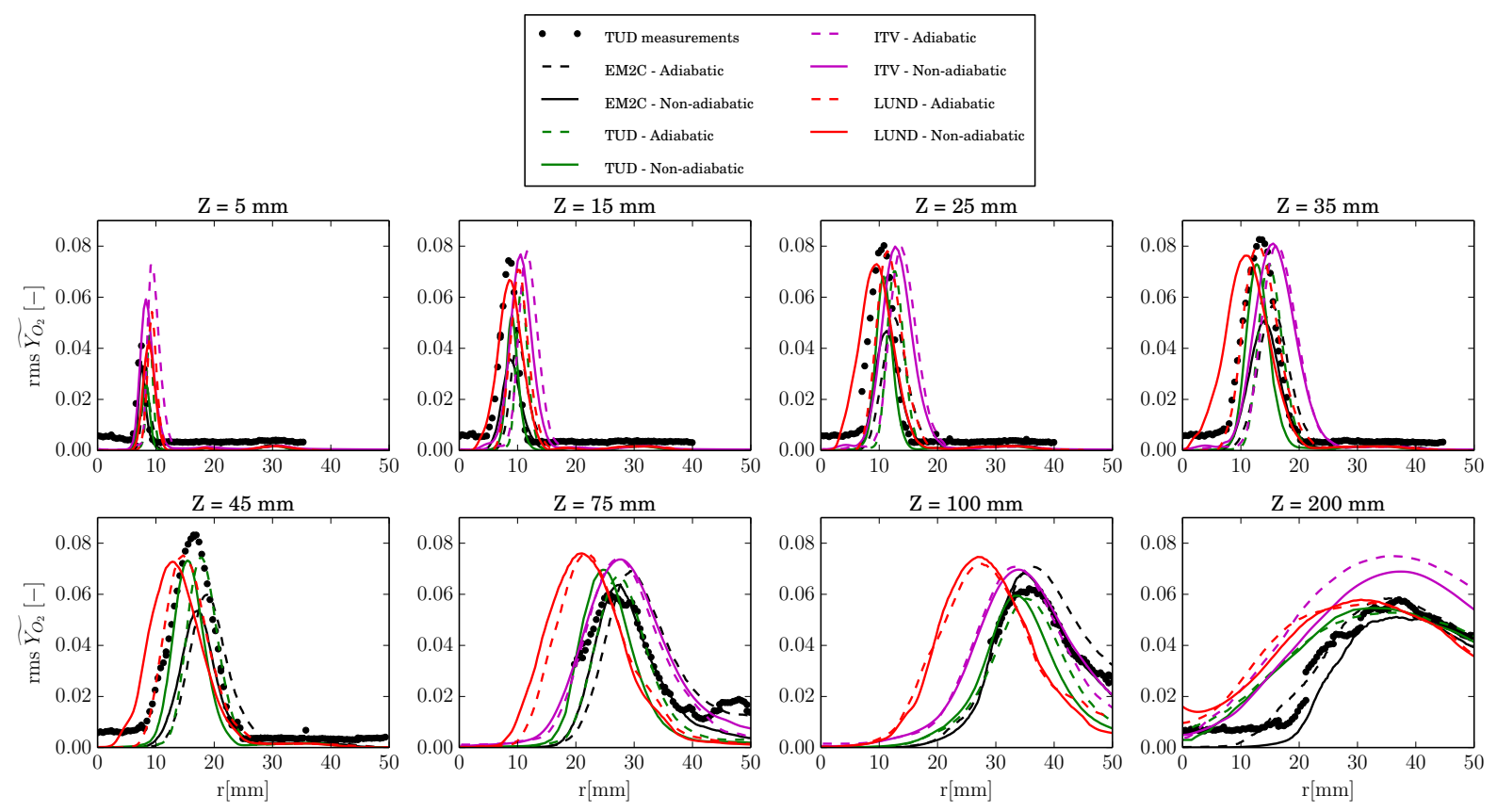

Figure A.25: RMS of $\mathrm{O}_{2}$ mass fraction at different axial positions. Solid lines: nonadiabatic LES, dashed lines adiabatic LES. 


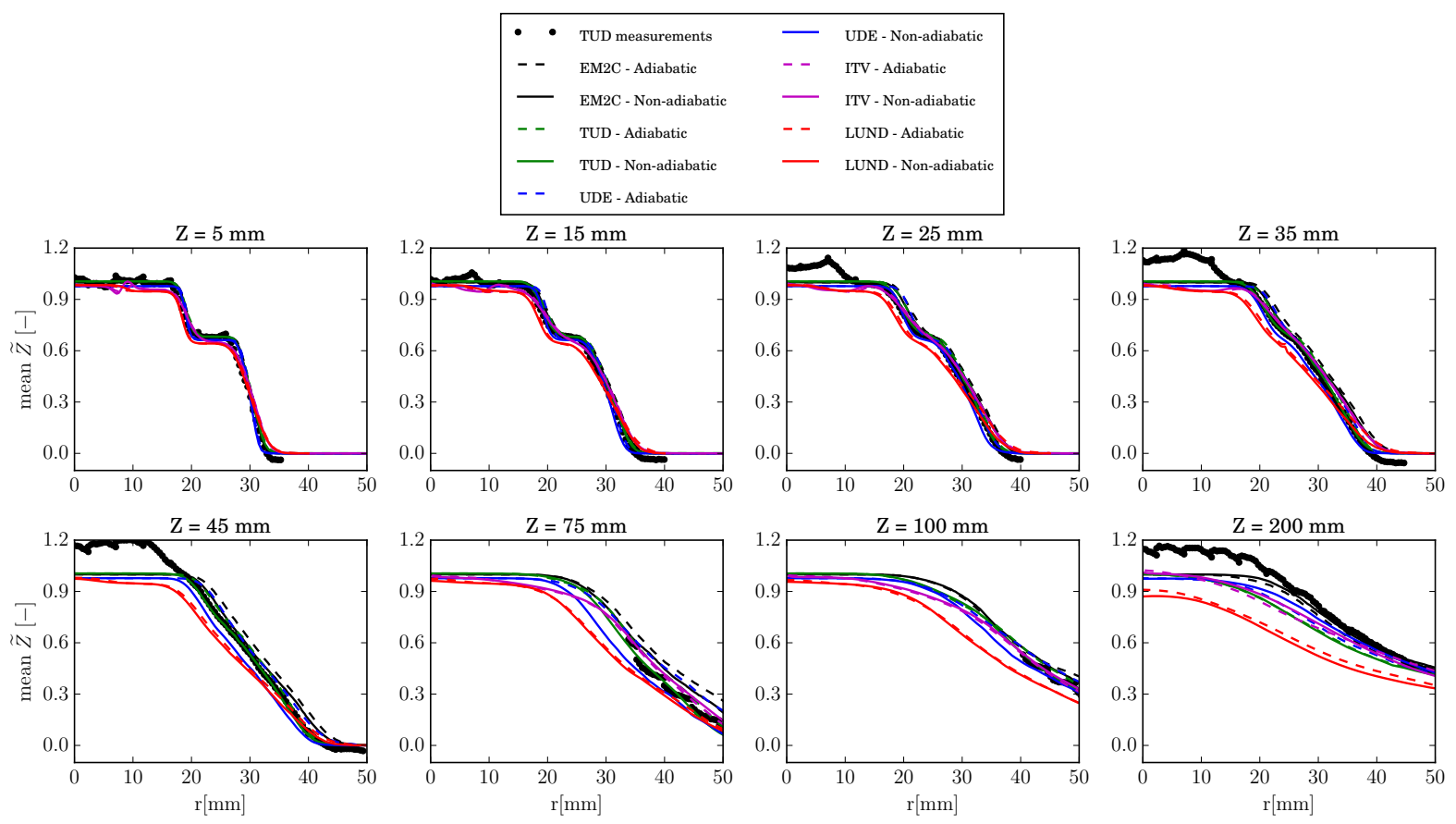

Figure A.26: Mean mixture fraction at different axial positions. Solid lines: non-adiabatic LES, dashed lines adiabatic LES. 


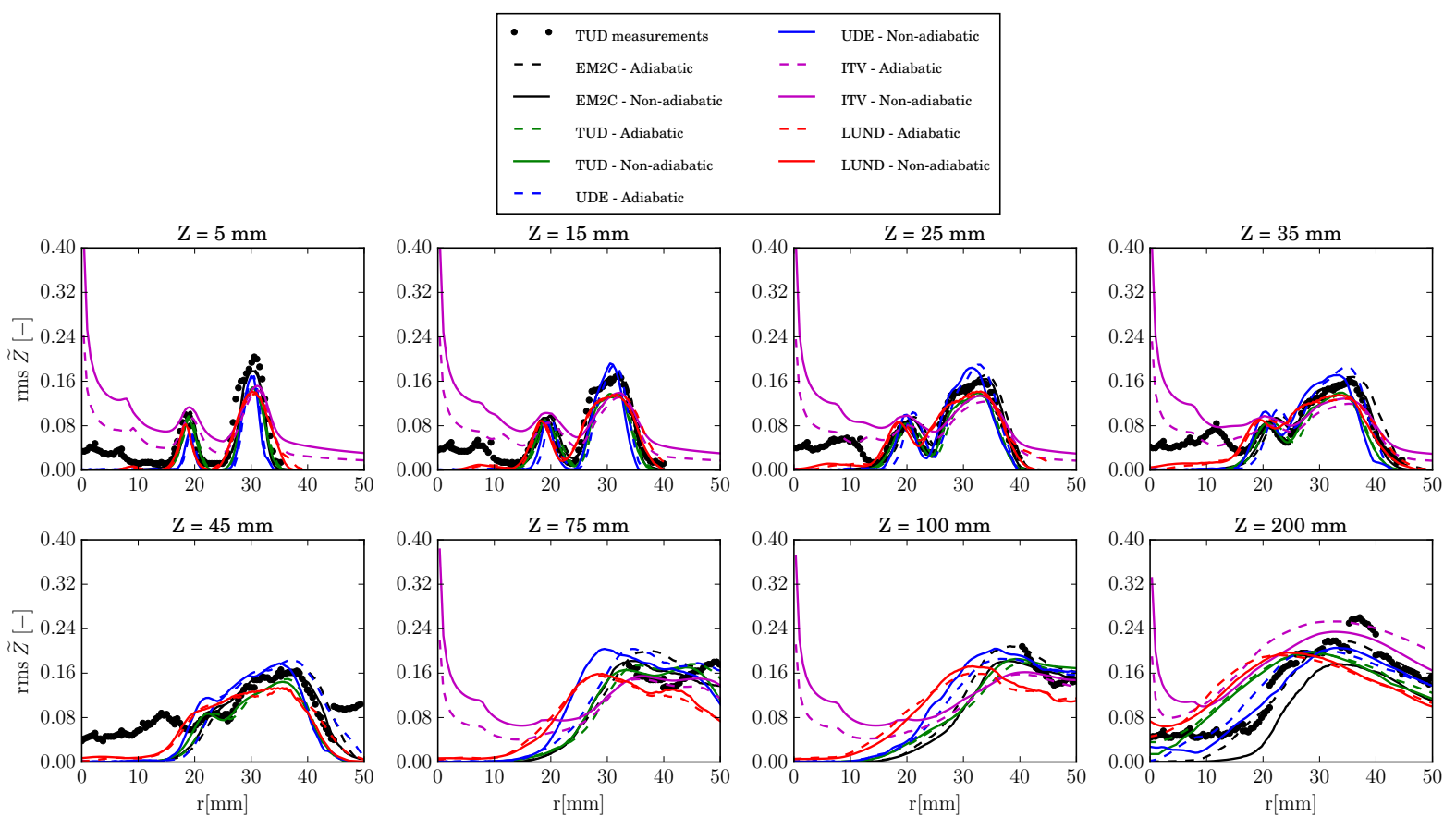

Figure A.27: RMS of mixture fraction at different axial positions. Solid lines: nonadiabatic LES, dashed lines adiabatic LES. 